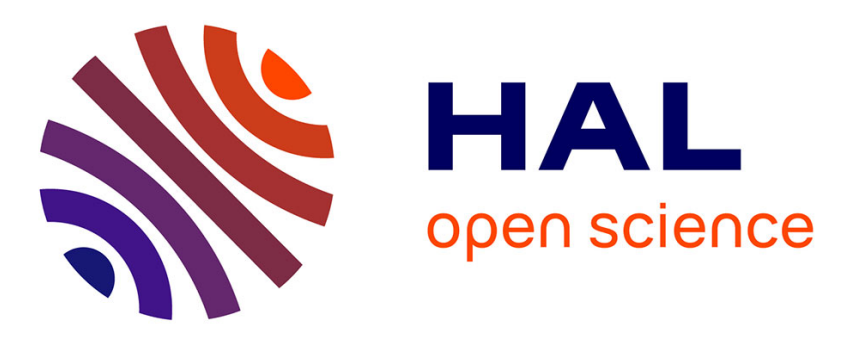

\title{
An analytical model for acoustic induced aluminum combustion fluctuations in solid rocket motors
}

\author{
Aurelien Genot, Stany Gallier, Thierry Schuller
}

\section{To cite this version:}

Aurelien Genot, Stany Gallier, Thierry Schuller. An analytical model for acoustic induced aluminum combustion fluctuations in solid rocket motors. AIAA Propulsion and Energy Forum 2018 Joint Propulsion Conference, Jul 2018, Cincinnati, United States. 10.2514/6.2018-4788 . hal-01871458

\author{
HAL Id: hal-01871458 \\ https://hal.science/hal-01871458
}

Submitted on 25 Sep 2018

HAL is a multi-disciplinary open access archive for the deposit and dissemination of scientific research documents, whether they are published or not. The documents may come from teaching and research institutions in France or abroad, or from public or private research centers.
L'archive ouverte pluridisciplinaire HAL, est destinée au dépôt et à la diffusion de documents scientifiques de niveau recherche, publiés ou non, émanant des établissements d'enseignement et de recherche français ou étrangers, des laboratoires publics ou privés. 


\title{
An analytical model for acoustic induced aluminum combustion fluctuations in solid rocket motors
}

\author{
Aurelien Genot* \\ CNES DLA, Centre National d'Etudes Spatiales, Direction des lanceurs, Paris, France \\ Stany Gallier ${ }^{\dagger}$ \\ ArianeGroup, Le Bouchet Research Center, Vert-le-Petit, France \\ Thierry Schuller \\ Laboratoire EM2C, CNRS, CentraleSupélec, Université Paris Saclay, Gif-sur-Yvette, France \\ Institut de Mécanique des Fluides de Toulouse, IMFT, Université de Toulouse, CNRS, Toulouse, France
}

In a Solid Rocket Motor, the combustion of aluminum droplets released by the solid propellant is often used to increase the thrust. The dynamics of this distributed combustion can drive thermo-acoustic instabilities. An analytical model for the local heat release rate fluctuations of the burning droplet cloud is derived and compared with previous low order models and with numerical flow simulations. This new model leads to close agreement with simulations and improve our understanding of the pressure oscillation source. Two contributions to heat release rate fluctuations are identified. The first one originates from the burning droplet cloud within the combustion volume and the second one lies at the combustion volume boundary between the burning cloud and the inert zone. The first contribution is the consequence of the response of the individual droplet dynamics to the flow oscillations and the second one is due to droplet lifetime oscillations. Both contributions depend on the droplet diameter, droplet velocity and gas velocity fluctuations. Models for diameter and droplet velocity fluctuations are derived by considering the peculiar structure of the acoustic boundary layer along the solid propellant surface with mass injection. The expressions for heat release rate fluctuations derived in this study can be used to predict the linear stability of a solid rocket motor at reduced computational costs.

\section{Nomenclature}

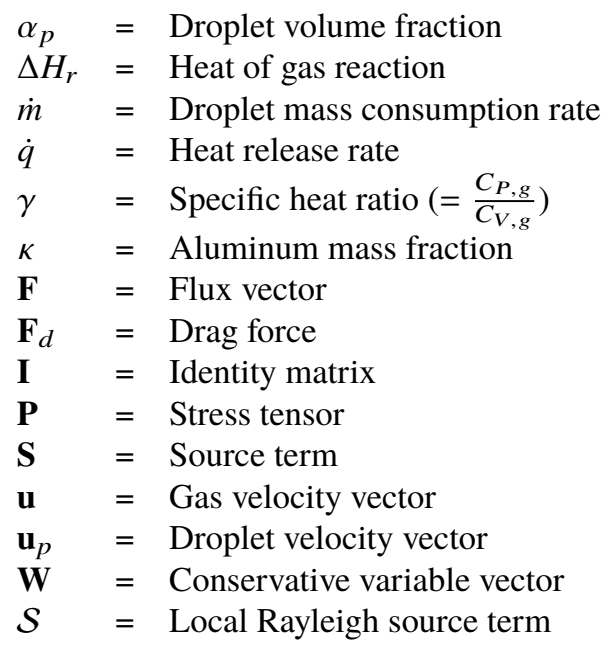

*PhD student, CNES/DLA, aurelien.genot@centralesupelec.fr

${ }^{\dagger}$ Research Engineer, Department of Aerodynamics and Combustion, stany.gallier@ariane.group

†Professor, thierry.schuller@imft.fr 


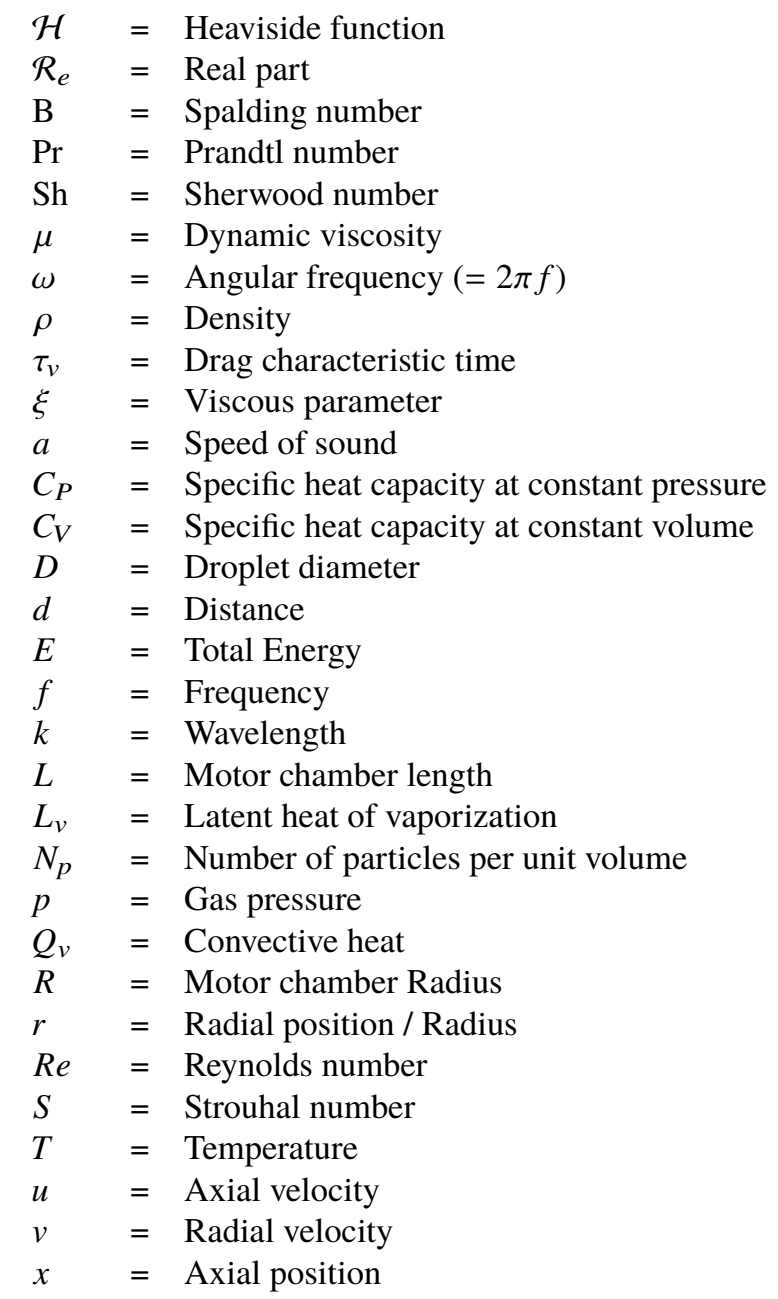

\section{Subscripts/Superscripts}

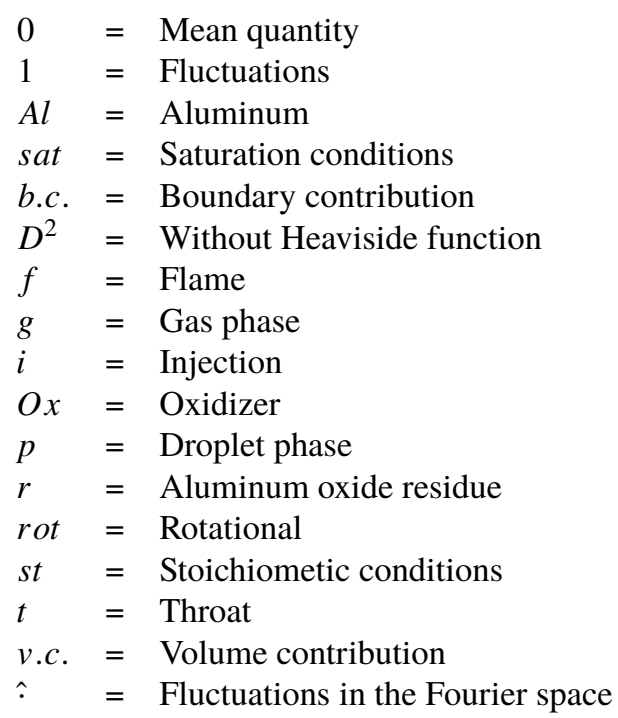




\section{Introduction}

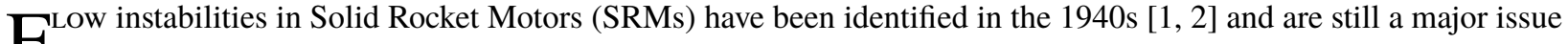
F for most motors including Ariane 5 or Ariane 6 programs [3, 4]. Blomshield [5] references a list of instabilities in Solid Rocket Motors, which can alter the ballistic pressure, the guidance, the thrust vector control or lead to motor structural failure. In solid propulsion, small pressure oscillations in the chamber may lead to high thrust oscillations [6] and all pressure oscillation sources need to be carefully addressed during the design process.

Solid propellant combustion instabilities generally develop in small lab scale motors because the combustion propellant response amplifies flow perturbations at high frequencies [7, 8]. Unsteady solid propellant combustion may couple with pressure or velocity fluctuations [2]. For larger motors, pressure oscillations are often due to hydrodynamic instabilities, as in Ariane 5 [2, 3]. In that case, large scale vortical structures are produced by the interaction of the flow with obstacles or a change of the propellant geometry at angles, or by the solid propellant injection itself and the pressure oscillation production is mainly due to vortex transport close to nozzle cavity [9-11], vortex ingestion in the nozzle [12, 13] and vortex shedding [14-16].

In aluminized solid propellers, aluminum droplets are released in the chamber [17,-19]. The droplets are ignited and constitute an additional energetic contribution to thrust the rocket. The gaseous products released from the burning droplets condense to form an aluminum oxide cap and finally yield inert droplets. These residual droplets are a source of acoustic losses for pressure oscillations [2, 20] and hinder the development of tangential or radial modes [21]. In the Sentry ballistic missile defense motor [5], aluminum combustion has however been suspected to drive instabilities. In Rijke burners, it has been proven experimentally, analytically and numerically that individual burning aluminum droplets can drive thermo-acoustic instabilities [22-24]. Also, many experiments in T-Burners with aluminized propellant show a combustion response due to the presence of aluminum droplets [4, 25, 26].

Numerical simulations [4, 27,-29] made in a generic Solid Rocket Motor (SRM) exhibit thermo-acoustic instabilities driven by the dynamics of the combustion of aluminum droplets. These simulations reveal that the dynamics of the burning aluminum droplets released from the solid propellant can couple with one of the low frequency acoustic modes of the motor chamber. Gallier et al. [30] demonstrated with a direct numerical flow simulation of a single aluminum droplet burning in an oscillating flow, that the burning droplet response is controlled by unsteady convection as evaporating droplets. Dupays and Vuillot [31, 32] proved that the mass release from a cloud of vaporizing droplets could drive acoustic waves. To better understand aluminum droplet driven combustion instabilities it is interesting to make a parallel with liquid-fueled systems, which can be also controlled by the droplet vaporization process [2, 33]. In hydrocarbon fuel spray systems, acoustic oscillations may (i) modify the droplet size distribution at the injector inlet [34, 35], (ii) segregate large from small droplets during their transport in the pulsed flow [36] and (iii) reduce the droplet evaporation time due to the additional drag from the pulsed flow [22, 30, 37]. Each of these mechanisms alters the flame dynamics. High-amplitude acoustic oscillations were also found to reduce the length of liquid fuel sprays [38]. Carvalho et al. [37] observed a reduction in the mean droplet lifetime due to acoustic forcing in their numerical model of a Rijke tube burning liquid droplets. This literature survey suggests that aluminum combustion is likely to be destabilizing and cause thermo-acoustic instabilities in SRMs. It has however received little attention so far and this work intends to shed light on the dynamics of burning droplets leading to heat release disturbances.

It is known that heat release fluctuations produced by the burning droplets and synchronized by the acoustic field are the main source of combustion driven instabilities in SRMs for positive Rayleigh index values [27]. To simplify the analysis, the other sources of instabilities are not considered in this work. The main objective is derive expressions for the heat release rate fluctuations produced by a cloud of burning droplets released from the propellant and which is submitted to acoustic perturbations.

In the next section, a reference computation in which the flow in a generic SRM is submitted to an acoustic pressure pulsation is analyzed to identify the thermo-acoustic sources. The governing equations computed by the flow solver are first recalled. Results are then analyzed to identify the different contributions to heat release fluctuations. The derivation of the low-order linear model for heat release rate disturbances from a cloud of burning aluminum droplets is described in section [V] In the same section, comparisons with a previous model from Gallier and Godfroy [27], the numerical flow simulations and the new model are presented. It is demonstrated that acoustic fluctuations lead to droplet velocity and droplet diameter disturbances and that both contributions need to be considered to reproduce the correct level of heat release fluctuation in the numerical flow simulations. 


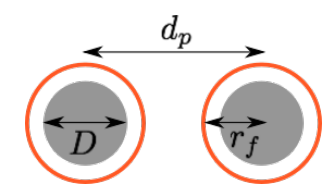

Fig. 1 Two burning droplets of diameter $D$ and flame radius $r_{f}$ separated by a distance $d_{p}$.

\section{Reference simulation}

\section{A. About group combustion for aluminum}

Aluminum combustion is usually assumed to take place in SRM in a distributed mode [23, 39]. However, the combustion regime depends on the droplet volume fraction. Group combustion effects are customarily evaluated with Chiu's approach [40, 41]. Nakamura et al. [42] identified two regimes of two-phase flow combustion, a "premixed-like combustion" and a "diffusion-like combustion" mode. In a premixed-like combustion regime, the oxidizer is initially present around each individual droplet whereas in a diffusion-like combustion mode, the oxidizer is only present at the boundary of the droplet cloud. For premixed-like combustion, Chiu's criterion overestimates the group behavior because it does not consider the effect of the initial oxygen concentration [42, 43].

Aluminum droplets are injected in SRMs with the gas products exhausting from the solid propellant combustion that are mainly composed of $\mathrm{CO}_{2}, \mathrm{H}_{2} \mathrm{O}, \mathrm{CO}$ and $\mathrm{N}_{2}$ [44]. The combustion reaction takes place between the aluminum droplets and the oxidizers $\mathrm{CO}_{2}$ and $\mathrm{H}_{2} \mathrm{O}$ [23]. Initially, at the injection surface, each aluminum droplet is surrounded by the oxidizer gas and therefore aluminum combustion can be classified as a premixed-like combustion regime. In this case, Chiu's approach is not relevant to validate the assumption of isolated burning aluminum droplets.

It is better to consider the mean inter-particle distance $d_{p}$ compared to the droplet flame radius $r_{f}$ as illustrated in Fig. 1 [39, 45, 46]. From percolation theory, a limit for isolated burning droplet may be derived [45, 47]:

$$
\frac{r_{f}}{d_{p}}<0.43
$$

The mean inter-particle distance $d_{p}$ can be evaluated as a function of the volumetric fraction $\alpha_{p}$ of droplets in the propellant and the droplet diameter $D[39,48]$ :

$$
\frac{d_{p}}{D}=\left(\frac{6 \alpha_{p}}{\pi}\right)^{-1 / 3}
$$

Aluminum droplets being oxidized by two reactants $\mathrm{CO}_{2}$ and $\mathrm{H}_{2} \mathrm{O}$, it is difficult to get reliable estimates of the flame radius $r_{f}$ from theory [47]. It has been decided to refer to experiments to evaluate the flame radius $r_{f}$. The measurements from Bucher et al. [49, 50] yield:

$$
\frac{r_{f}}{D} \simeq 1
$$

One third of the aluminum initially present forms agglomerates [51]. The remaining part burns very close to the solid propellant surface and is neglected in this analysis [27]. For a propellant loaded with a mass fraction of $18 \%$ of aluminum droplets and a mass fraction $\kappa=0.06$ of aluminum droplets released in the gas, the volumetric fraction $\alpha_{p}$ of droplets and the ratio $r_{f} / d_{p}$ are equal to:

$$
\alpha_{p}=4.10^{-5} \ll 1 \quad \frac{r_{f}}{d_{p}}=0.05<0.43
$$

The fraction $\alpha_{p}$ remaining small, a dilute particle phase is assumed. The ratio $r_{f} / d_{p}$ is also small enough to neglect group combustion effects and consider a distributed combustion of droplets burning individually.

\section{B. Governing equations}

A single class of spherical droplets, burning individually, is considered. Simulations are carried out by solving the compressible Navier-Stokes equations with the perfect gas law, in a two-way coupling Eulerian framework using Marble's two-phase flow model [27, 52]. This yields the following system of conservation equations:

$$
\frac{\partial}{\partial t}\left(\begin{array}{l}
\mathbf{W}_{\mathbf{g}} \\
\mathbf{W}_{\mathbf{p}}
\end{array}\right)+\nabla \cdot\left(\begin{array}{l}
\mathbf{F}_{\mathbf{g}} \\
\mathbf{F}_{\mathbf{p}}
\end{array}\right)=\left(\begin{array}{l}
\mathbf{S}_{\mathbf{g}} \\
\mathbf{S}_{\mathbf{p}}
\end{array}\right)
$$


where $\mathbf{W}_{\mathbf{g}}$ and $\mathbf{W}_{\mathbf{p}}$ denote the conservative variable vectors for the gas phase and the droplet phase respectively:

$$
\mathbf{W}_{\mathbf{g}}=\left(\begin{array}{c}
\rho_{g} \\
\rho_{g} \mathbf{u} \\
\rho_{g} E_{g}
\end{array}\right), \quad \mathbf{W}_{\mathbf{p}}=\left(\begin{array}{c}
\rho_{p} \alpha_{p} \\
\rho_{p} \alpha_{p} \mathbf{u}_{p} \\
\rho_{p} \alpha_{p} E_{p} \\
N_{p}
\end{array}\right)
$$

The flux vectors $\mathbf{F}_{\mathbf{g}}$ and $\mathbf{F}_{\mathbf{p}}$ for each phase are:

$$
\mathbf{F}_{\mathbf{g}}=\left(\begin{array}{c}
\rho_{g} \mathbf{u} \\
\rho_{g} \mathbf{u} \otimes \mathbf{u}-\mathbf{P} \\
\rho_{g} \mathbf{u} E_{g}-\mathbf{P} \cdot \mathbf{u}
\end{array}\right), \quad \mathbf{F}_{\mathbf{p}}=\left(\begin{array}{c}
\rho_{p} \alpha_{p} \mathbf{u}_{p} \\
\rho_{p} \alpha_{p} \mathbf{u}_{p} \otimes \mathbf{u}_{p} \\
\rho_{p} \alpha_{p} \mathbf{u}_{p} E_{p} \\
\mathbf{u}_{p} N_{p}
\end{array}\right)
$$

The source term vectors $\mathbf{S}_{\mathbf{g}}$ and $\mathbf{S}_{\mathbf{p}}$ are:

$$
\mathbf{S}_{\mathbf{g}}=\left(\begin{array}{c}
N_{p} \dot{m} \\
N_{p} \dot{m} \mathbf{u}_{\mathbf{p}}-\mathbf{F}_{\mathbf{d}} \\
N_{p} \dot{m}\left(E_{p}+L_{v}+\Delta H_{r}\right)-Q_{v}-\mathbf{F}_{\mathbf{d}} \cdot \mathbf{u}_{\mathbf{p}}
\end{array}\right), \quad \mathbf{S}_{\mathbf{p}}=\left(\begin{array}{c}
-\mathbf{S}_{\mathbf{g}} \\
0
\end{array}\right)
$$

where $\rho_{g}$ is the gas density, $\rho_{p}$ the droplet material density which is assumed to remain constant, $\mathbf{u}$ the gas velocity vector, $\mathbf{u}_{p}$ the droplet velocity vector, $E_{g}$ the gas total energy, $E_{p}$ the particle total energy, $N_{p}$ the number of particles per unit volume (coalescence and breakup are not considered), $\dot{m}$ the individual droplet mass consumption rate, $L_{v}$ the latent heat of vaporization, $\Delta H_{r}$ the heat of gas reaction, $Q_{v}$ the convective heat flux transferred by the hot gases to the droplet, $\mathbf{F}_{d}$ the drag force acting on the droplets and $\mathbf{P}$ the stress tensor of a Newtonian fluid given:

$$
\mathbf{P}=-p \mathbf{I}+\mu\left(\nabla \mathbf{u}+\nabla \mathbf{u}^{T}-\frac{2}{3}(\nabla \cdot \mathbf{u}) \mathbf{I}\right)
$$

with $p$ the gas pressure, $\mu$ the dynamic gas viscosity and $\mathbf{I}$ the identity matrix.

In this model, droplets have the same diameter $D$ in each computational cell given by:

$$
D=\left(\frac{6 \alpha_{p}}{\pi N_{p}}\right)^{1 / 3}
$$

Droplet combustion is assumed to obey the $\mathrm{D}^{2}$ law [53, 54]. The droplet mass release rate $\dot{m}_{D^{2}}$ is, under unit Lewis number assumption modeled by:

$$
\dot{m}_{D^{2}}=\pi D \frac{\mu}{\operatorname{Pr}} \ln (1+\mathrm{B}) \mathrm{Sh}
$$

where Pr is the Prandtl number, Sh the Sherwood number and B the thermal Spalding number expressed as [27]:

$$
\mathrm{B}=\frac{C_{P, g}\left(T_{g}-T_{p}\right)+\Delta H_{r}}{L_{v}}
$$

with $C_{P, g}$ the gas specific heat capacity at constant pressure, $T_{g}$ the gas temperature and $T_{p}$ the droplet temperature. To take into account the formation of inert aluminum oxide as combustion comes to its end [23, 28, 55], combustion is abruptly quenched when the droplet diameter falls below a critical value $D_{r}$. The droplet mass release is finally defined as:

$$
\dot{m}=\dot{m}_{D^{2}} \mathcal{H}\left(D-D_{r}\right)
$$

where $\mathcal{H}$ is the Heaviside function. The inert droplets with $D=D_{r}$ model the inert aluminum oxide residues. Note that this only models the large aluminum oxide residue. The aluminum oxide smoke resulting from combustion is not considered in this work [23].

Direct numerical flow simulations of a fixed burning aluminum droplet in an oscillating flow revealed that the droplet response to the pulsation is controlled by the convection response [30]. This convection response is well modeled by the 
Ranz-Marshall correlation [30, 56]. In the following simulations, the Sherwood number follows the Ranz-Marshall correlation:

$$
\mathrm{Sh}=2+0.6 \operatorname{Re}_{p}^{1 / 2} \operatorname{Pr}^{1 / 3}
$$

where the droplet Reynolds number is defined as:

$$
\operatorname{Re}_{p}=\frac{\rho_{g}\left|\delta \mathbf{u}_{\mathbf{p}}\right| D}{\mu} \quad \delta \mathbf{u}_{\mathbf{p}}=\mathbf{u}_{p}-\mathbf{u}
$$

The drag force $\mathbf{F}_{d}$ acting on a spherical and burning droplet is modeled by the Clift correlation [27, 57]:

$$
\mathbf{F}_{d}=-\frac{18 \mu \alpha_{p}\left(1+0.15 R e_{p}^{0.687}\right)}{D^{2}(1+\mathrm{B})} \delta \mathbf{u}_{\mathbf{p}}
$$

in which $\delta \mathbf{u}_{\mathbf{p}}$ is the relative droplet velocity with respect to the gaseous stream.

The Biot number being small, aluminum droplets are assumed isothermal during their combustion. The droplet temperature is taken equal to the saturation temperature of aluminum $T_{p}=T_{s a t}$. To be consistent, it is also assumed that all the convective heat flux $Q_{v}$ from the hot gases is used to sustain droplet evaporation:

$$
Q_{v}=N_{p} \dot{m} L_{v}
$$

This approximation simplifies the source terms $\mathbf{S}_{\mathbf{g}}$ and $\mathbf{S}_{\mathbf{p}}$ in Eq. (8). When the droplet diameter reaches the critical value $D=D_{r}$, the convective heat flux $Q_{v}$ around inert aluminum oxide particles is modeled as in [27]. In this framework, the volumetric heat release rate due to aluminum combustion corresponds to:

$$
\dot{q}=N_{p} \dot{m}\left(\Delta H_{r}+C_{V, p} T_{p}-C_{V, g} T_{g}+\frac{\delta \mathbf{u}_{p}^{2}}{2}\right)
$$

where $C_{V, p}=C_{P, p}$ denotes the droplet specific heat capacity and $C_{V, g}$ stands for the gas specific heat capacity at constant volume. One also defines $\dot{q}_{D^{2}}$ the heat release rate that would be produced if combustion had proceed until complete evaporation of aluminum droplets. In this case, the aluminum consumption rate $\dot{m}$ defined by Eq. (13) with aluminum oxide is replaced in Eq. (18) by $\dot{m}_{D^{2}}$ given by Eq. (11):

$$
\dot{q}_{D^{2}}=N_{p} \dot{m}_{D^{2}}\left(\Delta H_{r}+C_{V, p} T_{p}-C_{V, g} T_{g}+\frac{\delta \mathbf{u}_{p}^{2}}{2}\right)
$$

\section{Numerical modeling}

The numerical model is described in [27--29]. Simulations are made with CPS, an in-house ArianeGroup flow solver [58]. The governing equations are discretized and resolved by a finite volume technique adapted to unstructured meshes. The numerical schemes are second order accurate in space (MUSCL approach) and second order accurate in time using explicit two-step Runge-Kutta time stepping. The time step is limited by a Courant-Friedrichs-Lewy (CFL) condition set to $C F L=0.55$.

Simulations shown in this work are carried out in a 2D axisymmetric framework. The configuration explored is a cylindrical motor, with a radial injection of mass modeling the solid propellant combustion, where gas and aluminum droplet are released, and an exit boundary condition, at the end of the nozzle. The solid propellant burning velocity is neglected and the geometry is fixed in these simulations because the flow velocity is much higher than the solid propellant burning velocity. The computed geometry is shown in Fig. 2. The chamber has a radius $R=0.593 \mathrm{~m}$, a length $L=7 \mathrm{~m}$ and a symmetry axis at $r=0$. The nozzle has a throat of radius $R_{t}=0.175 \mathrm{~m}$, which is located at $x_{t}=7.3 \mathrm{~m}$ away from the motor head-end $x=0$.

The computational grid is composed of 360,000 quads with about 600 points in the axial direction and 600 points in the radial direction. The grid is clustered near the propellant burning surface to resolve the aluminum distributed combustion. The region where the combustion reaction takes place is indicated in red in Fig. 2. The smallest grid spacing at the propellant surface is about $0.1 \mathrm{~mm}$. It is worth noting that turbulence is not taken into account in these simulations to focus the analysis on the coupling between acoustics and aluminum droplet unsteady combustion 


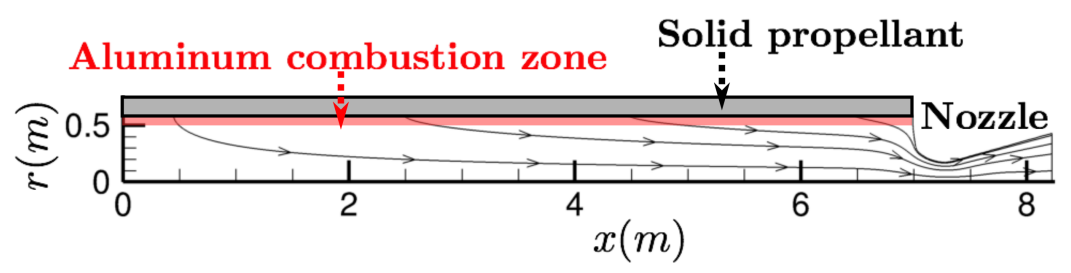

Fig. 2 Solid rocket motor (SRM) with aluminized propellant. Aluminum droplet combustion is delineated by the red zone. A few gas streamlines calculated at steady condition (without acoustic forcing) are also plotted.

[27, 59, 60] without dealing with the complexity of interactions with turbulence. Grid convergence has been checked and no significant differences have been noted.

No-slip conditions are used for the gaseous and particle phases at the wall boundaries including the head-end and the nozzle. Solid propellant burning is modeled through the lateral boundary of the numerical domain between $x=0$ and $L$ by injection of gas at a constant mass flow rate with a velocity vector normal to the surface and pointing inwards. Gas and aluminum droplets are injected radially at the same velocity $v_{p i}=v_{i}$. The mass flow rate of the two-phase droplet and gaseous mixture released from the solid propellant combustion is set to $(\rho v)_{i}=24.6 \mathrm{~kg} \cdot \mathrm{m}^{-2} \cdot \mathrm{s}^{-1}$. Considering only the aluminum agglomerates, the mass fraction of injected aluminum droplet is set to $\kappa_{i}=0.06$ [44, 51]. The response of the solid propellant combustion rate to acoustic oscillations is not considered here to focus the analysis on aluminum combustion driven instabilities.

Aluminum droplets have an initial diameter $D_{i}=120 \mu \mathrm{m}$ (for aluminum agglomerates) and the aluminum oxide residue diameter is fixed to $D_{r}=50 \mu \mathrm{m}[28,51,61]$. Aluminum particles are injected from the solid propellant surface at the saturation temperature $T_{p, i}=T_{s a t}=2791 \mathrm{~K}$. The injected gas is at the temperature $T_{g, i}=3440 \mathrm{~K}$. The specific heat capacity at constant pressure of the gaseous phase is fixed to $C_{P, g}=1997 \mathrm{~J} \cdot \mathrm{kg}^{-1} \cdot \mathrm{K}^{-1}$ and to $C_{P, p}=1177$ $\mathrm{J} . \mathrm{kg}^{-1} \cdot \mathrm{K}^{-1}$ for the aluminum droplets. The specific heat capacity ratio of the gas is $\gamma=\frac{C_{P, g}}{C_{V, g}}=1.16$. The latent heat of aluminum droplet vaporization is $L_{v}=10.8 \times 10^{6} \mathrm{~J} / \mathrm{kg}$ and the heat of reaction per unit mass, after vaporization, is $\Delta H_{r}=9.53 \times 10^{6} \mathrm{~J} / \mathrm{kg}$. Gas and aluminum droplet properties used in these simulations are summarized in Table 1 .

Table 1 Gas and aluminum droplet properties in the SRM

\begin{tabular}{cc|cc}
\hline \hline$\mu$ & $9.1 \times 10^{-5} \mathrm{~kg} / \mathrm{m} / \mathrm{s}$ & $P r$ & 0.4 \\
$D_{i}$ & $120 \mu \mathrm{m}$ & $D_{r}$ & $50 \mu \mathrm{m}$ \\
$(\rho v)_{i}$ & $24.6 \mathrm{~kg} \cdot \mathrm{m}^{-2} \mathrm{~s}^{-1}$ & $\Delta H_{r}$ & $9.53 \times 10^{6} \mathrm{~J} / \mathrm{kg}$ \\
$\kappa_{i}$ & $6 \%$ & $L_{v}$ & $10.8 \times 10^{6} \mathrm{~J} / \mathrm{kg}$ \\
$T_{g, i}$ & $3440 \mathrm{~K}$ & $T_{\text {sat }}$ & $2791 \mathrm{~K}$ \\
$C_{P, g}$ & $1997{\mathrm{~J} . \mathrm{kg}^{-1} \cdot \mathrm{K}^{-1}}$ & $C_{P, p}$ & $1177 \mathrm{~J}_{\mathrm{kg}}{ }^{-1} \cdot \mathrm{K}^{-1}$ \\
$\gamma$ & 1.16 & $f$ & $70.45 \mathrm{~Hz}$ \\
$\hat{\eta}$ & $4200 \mathrm{~Pa}$ & & \\
\hline \hline
\end{tabular}

\section{Simulation results}

The configuration investigated is found to be thermo-acoustically stable. Acoustic excitation is imposed at the head-end boundary at $x=0$ with a pressure pulsation of amplitude $\hat{\eta}=4200 \mathrm{~Pa}$ locked on the first longitudinal mode $f=70.45 \mathrm{~Hz}$ of the SRM. The resulting acoustic field is a standing wave in the SRM with hard wall acoustic boundaries at both extremities. It was checked that the forcing level $\hat{\eta} / p_{0}=4 \cdot 10^{-4}$ is small enough compared to the mean pressure $p_{0} \approx 100$ bars to get linear pressure and heat release rate fluctuations. The oscillation level corresponds to half the pressure level observed at limit cycle of the unstable cases studied in [28, 29]. The response of the heat release rate due to aluminum combustion is shown in Fig. 3 at four regularly distributed instants in a forcing cycle. This figure gives a zoom over the aluminum combustion region along the SRM. Droplets are injected at $r / R=1$ and a few droplet streamlines are indicated by the blue arrows in Fig. 3, showing that the droplets are crossing the combustion region with a quasi-radial path. 


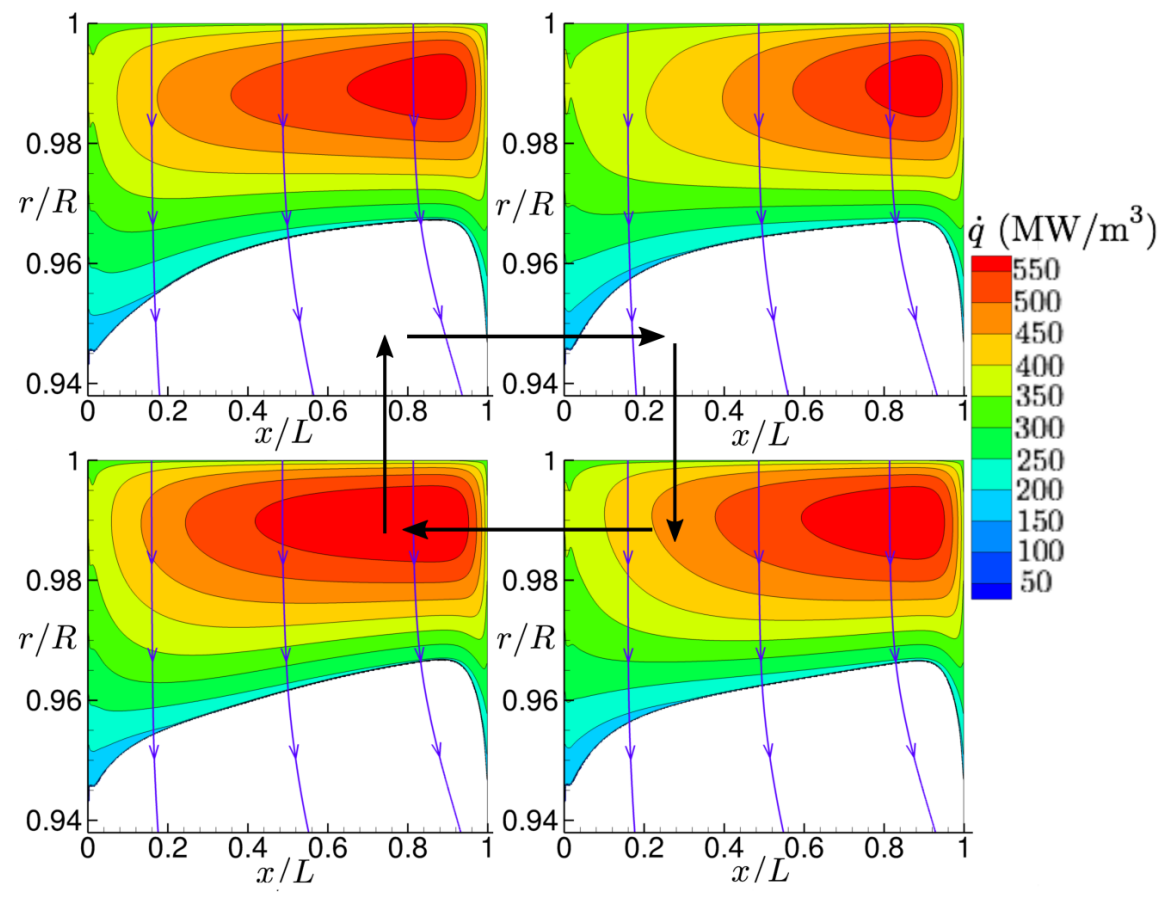

Fig. 3 Heat release rate due to aluminum combustion $\dot{q}$ at four instants in an oscillation cycle at $f=70 \mathrm{~Hz}$. This figure is zoomed over the aluminum combustion zone and is stretched in the radial direction. Aluminum droplets are injected radially at $r / R=1$. A few droplet streamlines are represented by the blue arrows highlighting the quasi-radial droplet trajectories through the combustion zone.

During a period of oscillation, axial fluctuations of the volumetric heat release rate $\dot{q}$ can be identified throughout the combustion volume in Fig. 3 This contribution is associated to disturbances of the individual combustion rate of aluminum droplets due to the axial acoustic velocity fluctuations as described in [27, 30]. This contribution to the thermo-acoustic source is designated in this study as the volumetric source [28].

The second striking feature in Fig. 3 is a flapping motion of the combustion volume boundary corresponding to the region where the aluminum droplet diameter has reached its critical value $D=D_{r}$ separating the combustion zone with $D>D_{r}$ and the inert zone filled with inert aluminum oxide particles with diameter $D_{r}$. This motion takes essentially place in the radial direction while the acoustic mode is controlled by an axial oscillation. It has recently been shown that this motion results from droplet lifetime oscillations [29]. This contribution to heat release rate fluctuations originating from droplet lifetime oscillations is designated in this work as the boundary contribution.

Sound production in a thermo-acoustic instability is due to the coupling between pressure and heat release rate fluctuations, which are here associated to the behavior of unsteady aluminum particle combustion. To highlight this coupling, the local Rayleigh source term $\mathcal{S}$ is plotted in Fig. 4 and given by [62]:

$$
\mathcal{S}=\frac{\gamma-1}{\gamma p_{0} T} \int_{T} p_{1} \dot{q}_{1} d t
$$

In this figure, the axes are again zoomed over the aluminum combustion zone shown in red in Fig. 2 and are stretched in the radial direction. In Fig. 4, the red colors correspond to positive values of the Rayleigh source term $\mathcal{S}$ and are associated to regions of the flow characterized by sound production and the blue colors correspond to the negative values for $\mathcal{S}$ and are associated to regions of the flow with acoustic damping.

This means the unsteady combustion at the head end destabilizes the system, while the combustion taking place close to the nozzle stabilizes the SRM. The sign of $\mathcal{S}$ also depends on the acoustic mode which is considered and which is here the first longitudinal mode of the SRM. High contributions to $\mathcal{S}$ are visible in the volume and at the boundary in the flapping region, indicating that both volume and boundary contributions to heat release rate oscillations identified in Fig. 3 need to be considered in the production/damping of sound by unsteady aluminum combustion. Similar features have also been observed at limit cycles of thermo-acoustic instabilities when $\hat{\eta} / p_{0}<5.10^{-3}$ in [28, 29]. 


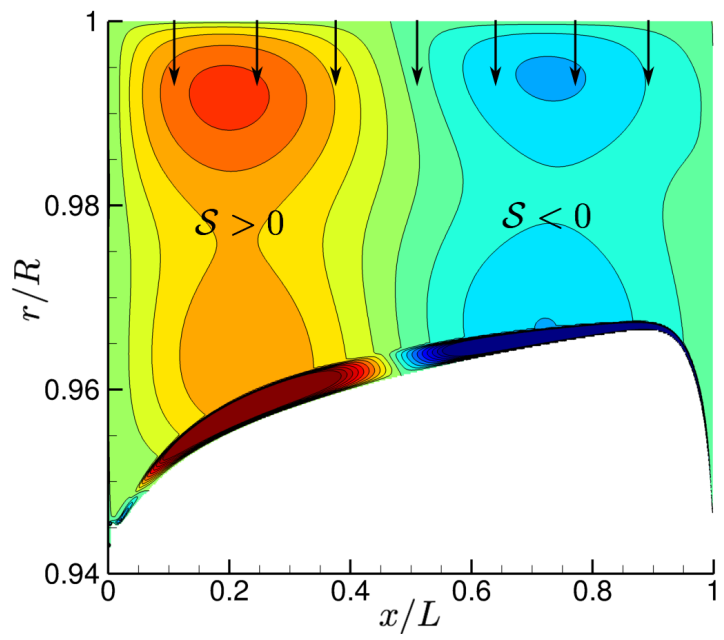

Fig. 4 Local Rayleigh source term $\mathcal{S}=\frac{\gamma-1}{\gamma p_{0} T} \int_{T} p_{1} \dot{q}_{1} d t$ zoomed over the aluminum combustion zone which has been stretched in the radial direction. Aluminum droplets are injected radially at $r / R=1$ in equilibrium with the propellant burnt gas velocity.

Due to the radial mass injection at $r / R=1$ in a SRM, the mean flow is turning from the radial direction to the axial direction before its expulsion through the nozzle [2]. This rotation of the mean flow leads to additional contributions to velocity disturbances when the system is submitted to axial flow perturbations at its boundaries. The acoustic boundary layer where aluminum combustion takes place has in this case a very peculiar structure [2, 63, 65]. This structure calculated with CPS is illustrated by plotting the modulus of the axial gas velocity fluctuation $\hat{u}$ in Fig. 5 at a distance $x / L=1 / 4$ corresponding to the quarter of the SRM with respect to the chamber end. Results are normalized in this figure by the acoustic velocity fluctuation $\hat{u}_{a c}$ that settles along the SRM axis. This value would be reached throughout the entire cross section of the motor $\hat{u}=\hat{u}_{a c}$ for an inviscid flow without mean flow rotation. This figure shows that aluminum combustion takes place within this acoustic boundary layer. This structure has to be taken into account to understand the response of aluminum droplets to flow disturbances.

\section{Linear aluminum combustion response model}

Due to the small size of the droplets and the low forcing frequencies investigated in this work, the droplet response to acoustic perturbations is assumed to be quasi-steady [30, 34, 66]. This property is used in the following to develop an unsteady combustion model with the same quasi-steady approximation and by linearizing the governing equations shown in section III.B around the mean flow.

As the system is submitted to acoustic harmonic forcing at frequency $f$, all signals of the physical variables are assumed to be also harmonic at the same frequency. The signal $X$ is decomposed as $X=X_{0}+X_{1}$, where the mean is given by:

$$
X_{0}=\frac{1}{T} \int_{T} X d t
$$

with $T=1 / f$ the acoustic period. The subscript 1 stands for the perturbed state around the mean value designated by the subscript 0 . The Fourier transform is computed as:

$$
\hat{X}=\int_{T} X \exp (-i \omega t) d t \quad \omega=2 \pi f
$$

where $\hat{\bullet}$ stands for Fourier component of the perturbation and the inverse Fourier transform yields the disturbance:

$$
X_{1}=\mathcal{R}_{e}(\hat{X} \exp (i \omega t))
$$

The model for heat release disturbances produced by acoustic pulsations from Gallier and Godfroy [27] is briefly recalled and results are compared to direct numerical flow simulations. Analytical developments are then carried out to 


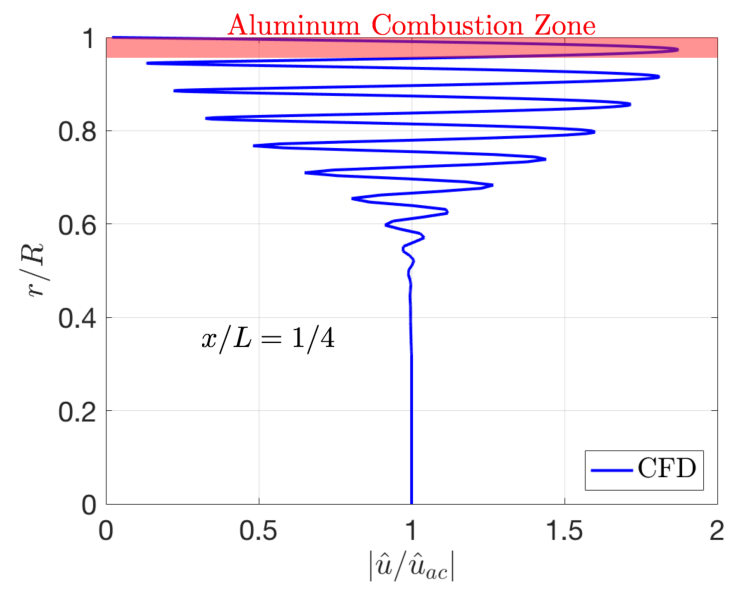

Fig. 5 Velocity fluctuation in the acoustic boundary layer of the SRM at $x / L=1 / 4$. The zone covered by aluminum combustion is emphasized.

better model the droplet dynamics and the resulting heat release rate disturbances by considering fluctuations of the droplet diameter and the motion of the aluminum combustion boundary of the pulsed flow.

\section{A. Model from Gallier and Godfroy [27]}

In Appendix A of [27], Gallier and Godfroy derived an expression for the response of heat release rate disturbances $\hat{\dot{q}}$ from aluminum droplets due to acoustic forcing. They used the same governing equations as in this study. They first demonstrated that heat release rate fluctuations $\hat{\dot{q}}$ overwhelm drag force work and kinetic energy in the production of pressure oscillations and may be recast as (Eq. $18 \mathrm{p})$ :

$$
\hat{\dot{q}}=\widehat{N_{p} \dot{m}}\left(\Delta H_{r}+C_{V, p} T_{s a t}-C_{V, g} T_{g, 0}+\frac{\left|\delta \mathbf{u}_{\mathbf{p}}\right|_{0}^{2}}{2}\right)
$$

where fluctuations of the reaction heat is also neglected. The corresponding mean heat release rate $\dot{q}_{0}$ is given by:

$$
\dot{q}_{0}=N_{p, 0} \dot{m}_{0}\left(\Delta H_{r}+C_{V, p} T_{s a t}-C_{V, g} T_{g, 0}+\frac{\left|\delta \mathbf{u}_{\mathbf{p}}\right|_{0}^{2}}{2}\right)
$$

These expressions can be rewritten as:

$$
\frac{\hat{\dot{q}}}{\dot{q}_{0}}=\frac{\hat{N}_{p}}{N_{p, 0}}+\frac{\hat{\dot{m}}}{\dot{m}_{0}}
$$

Relative fluctuations of the droplet number density $\hat{N}_{p} / N_{p, 0}$ are second order terms with respect to $\hat{\dot{m}} / \dot{m}_{0}$ [27]. Neglecting diameter fluctuations $\hat{D}$, gas temperature fluctuations $\hat{T}_{g}$, gas density fluctuations $\hat{\rho}_{g}$, radial velocity fluctuations $\hat{v}$ and $\hat{v}_{p}$ [27, 64], linearization of $\dot{m}$ in Eq. (13) yields:

$$
\frac{\hat{\dot{q}}}{\dot{q}_{0}}=\frac{\hat{\dot{m}}}{\dot{m}_{0}}=\frac{\mathrm{Sh}_{0}-2}{2 \mathrm{Sh}_{0}} \frac{\delta u_{p, 0}}{\left|\delta \mathbf{u}_{\mathbf{p}}\right|_{0}^{2}}\left(\hat{u}_{p}-\hat{u}\right)
$$

In this model, heat release rate fluctuations $\hat{\dot{q}}$ solely result from axial droplet velocity $\hat{u}_{p}$ and gas velocity $\hat{u}$ fluctuations. The droplet velocities $\hat{u}_{p}$ can be formulated as a function of the axial gas velocity fluctuations $\hat{u}$. Combining the momentum conservation with the mass conservation of the droplet phase (Eqs. (5)-(8)) leads to the following transport equation (in the axial direction):

$$
\frac{\partial u_{p}}{\partial t}+u_{p} \frac{\partial u_{p}}{\partial x}+v_{p} \frac{\partial u_{p}}{\partial r}=-\frac{\delta u_{p}}{\tau_{v}}
$$

where $\tau_{v}$ is the droplet drag characteristic time:

$$
\tau_{v}=\frac{1+B}{1+0.15 \operatorname{Re}_{p}^{0.687}} \frac{\rho_{p} D^{2}}{18 \mu}
$$




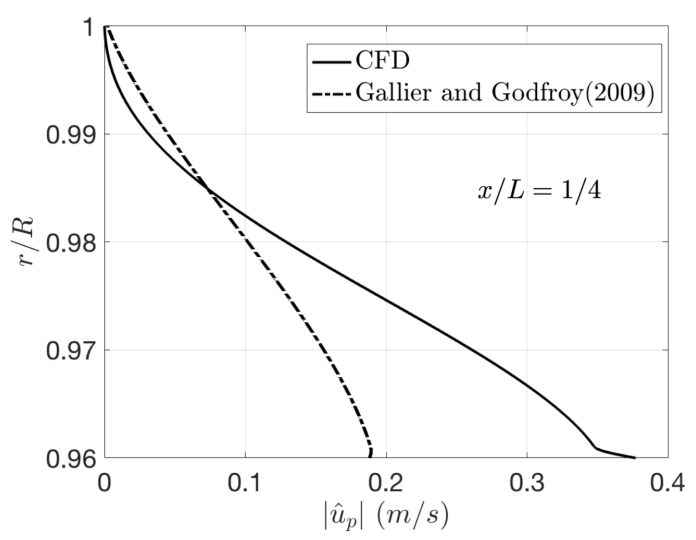

Fig. 6 Axial droplet velocity fluctuation modulus at $x / L=1 / 4$, in the aluminum combustion zone, calculated with Eq. [32) used by Gallier and Godfroy [27] and by direct numerical flow simulation. Gas velocity fluctuations $\hat{u}$ and mean drag characteristic time $\tau_{v, 0}$, in Eq. [32), are extracted from the CFD simulation.

Neglecting radial velocity fluctuations $v_{p} \simeq v_{p, 0}$ [2, 64], Eq. 28] yields to the first order approximation:

$$
\frac{\partial u_{p, 1}}{\partial t}+u_{p, 1} \frac{\partial u_{p, 0}}{\partial x}+u_{p, 0} \frac{\partial u_{p, 1}}{\partial x}+v_{p} \frac{\partial u_{p, 1}}{\partial r}=-\frac{\delta u_{p, 1}}{\tau_{v, 0}}+\frac{\delta u_{p, 0}}{\tau_{v, 0}^{2}} \tau_{v, 1}
$$

By further neglecting the advection terms and the fluctuating drag characteristic time in Eq. [30] [31], it comes:

$$
\frac{\partial u_{p, 1}}{\partial t}=-\frac{\delta u_{p, 1}}{\tau_{v, 0}}
$$

In the Fourier space, Eq. 31] gives [20, 31]:

$$
\hat{u}_{p}=\frac{\hat{u}}{1+i \omega \tau_{v, 0}}
$$

Substituting Eq. (31) in Eq. (27), one finally obtains:

$$
\frac{\hat{\dot{q}}}{\dot{q}_{0}}=-\frac{\mathrm{Sh}_{0}-2}{2 \mathrm{Sh}_{0}} \frac{\omega \tau_{v, 0}\left(i+\omega \tau_{v, 0}\right)}{1+\omega^{2} \tau_{v, 0}^{2}} \frac{\delta u_{p, 0}}{\left|\delta \mathbf{u}_{\mathbf{p}}\right|_{0}^{2}} \hat{u}
$$

This transfer function gives the heat release rate fluctuations as a function of the mean flow and axial gas velocity fluctuations $\hat{u}$. The two expressions Eqs. (32) and (33) are compared to numerical flow simulations in Figs. 6 and 77, at the quarter of the motor chamber $x / L=1 / 4$ and in the aluminum combustion zone. To be consistent, the mean flow properties in Eqs. (32) and (33) are taken from the simulation.

The modulus of the axial droplet velocity fluctuation $\left|\hat{u}_{p}\right|$ is plotted in Fig. 6 . The analytical model Eq. (32) reproduces roughly the behavior observed in the simulation close to the propellant surface at $r / R \sim 1$, but the results rapidly deviate as the distance to the propellant surface increases. This means that the low-pass filter model in Eq. (32) does not model correctly the axial droplet velocity fluctuations $\hat{u}_{p}$ in the aluminum combustion zone.

Figure 7 now shows the modulus of the heat release rate fluctuations resulting from aluminum combustion. Numerical results from the flow solver are compared to the analytical expression Eq. [33] from Gallier and Godfroy [27] and to predictions from Eq. 27p where the axial gas velocity $\hat{u}$ is taken from the flow solver. The only difference with predictions from Eq. (33) is that in the former model droplet velocity fluctuations $\hat{u}_{p}$ are modeled with Eq. 32) and in the second one they are taken from the flow simulations.

It has been shown that the droplet velocity is not well reproduced by Eq. 333 in Fig. 6) and the heat release rate fluctuation is also not well reproduced in Fig. 7 with this model. Taking the correct gas $\hat{u}$ and particle $\hat{u}_{p}$ velocities improves the predictions with respect to the numerical flow simulation close to the propellant surface, but the heat release rate model Eq. 27) does not allow to reproduce the correct trend over the entire combustion volume with important differences close to the boundary where droplet combustion is quenched. The numerical flow simulation 


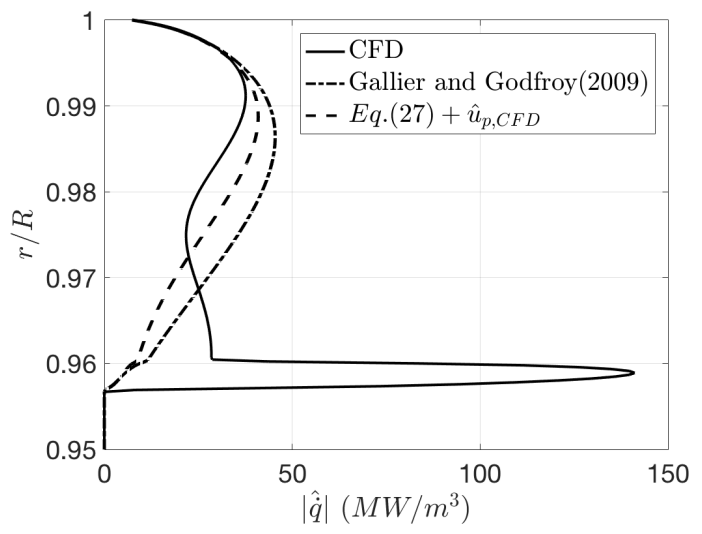

Fig. 7 Heat release rate fluctuation modulus at $x / L=1 / 4$ in the aluminum combustion zone calculated with Eq. 33] from Gallier and Godfroy [27] and with Eq. 27]. Gas and droplet velocity fluctuations $\left(\hat{u}, \hat{u}_{p}\right)$ and mean flow are taken from the simulation. Results are also compared to direct flow simulations.

highlights a high peak of heat release oscillation close to the boundary of the aluminum combustion zone. This peak results from the motion of the combustion volume boundary and is not reproduced by the analytical models. It has however been shown that this motion largely contributes to thermo-acoustic pressure oscillation source [28, 29].

In the following section, a new model is developed that better reproduces the heat release rate fluctuations inside the combustion volume and at the volume boundary.

\section{B. Analytical model improvements}

Aluminum droplet lifetime is driven by the condition on the droplet diameter $D=D_{r}$, represented mathematically by the Heaviside function in Eq. (13), which is used to abruptly quench combustion. It has been demonstrated in [29] that droplet lifetime oscillations are likely to induce a fluctuating motion $\hat{r}_{c}$ of the boundary of the distributed combustion volume as in Fig. 3 This motion constitutes an additional source of heat release fluctuations and another thermo-acoustic source [28, 29] (see Fig. 4).

Heat release rate fluctuations observed at the boundary of the combustion zone and corresponding to the high peak in Fig. 7] originate from fluctuations of the Heaviside function and of the droplet diameter [29]. In Eqs. (18) and (13), neglecting droplet diameter fluctuations removes the impact of the Heaviside function and the source of heat release rate fluctuations due to the lifetime droplet oscillations.

Considering a linear response of the heat release, fluctuations are decomposed as the sum of a volumetric contribution v.c. and a contribution b.c. from the boundary where (Eq. (13)):

$$
\left.\hat{\dot{q}}=\hat{\dot{q}}_{v . c .}+\hat{\dot{q}}_{\text {b.c. }}=\hat{\dot{q}}_{D^{2}}\left(\mathcal{H}\left(D-D_{r}\right)\right)_{0}+\dot{q}_{D^{2}, 0} \mathcal{H ( D - D _ { r }}\right)
$$

The boundary contribution can be expressed in the Fourier space as [29]:

$$
\hat{q}_{b . c .}=-\dot{q}_{D^{2}, 0} \frac{2\left(1-\left(\frac{r-r_{c, 0}}{\left|\hat{r}_{c}\right|}\right)^{2}\right)^{1 / 2}}{\pi\left|\hat{r}_{c}\right|} \hat{r}_{c}
$$

where $r_{c}$ is the radial position of the combustion volume boundary, $\hat{r}_{c}$ the radial Fourier component disturbance and $r_{c, 0}$ the mean position of this boundary. This model is restricted to radial fuel droplet trajectories which is a reasonable approximation due to the small thickness of the combustion volume. This contribution results from local nonlinearities of the heat release rate at the end of the combustion process. The mean boundary position $r_{c, 0}$ is given by [29]:

$$
r_{c, 0}=R+\frac{2}{D_{i}^{2}-D_{r}^{2}} \int_{D_{i}}^{D_{r}} t_{c, 0} v_{p} D_{0} d D
$$

with $t_{c, 0}$ the mean droplet lifetime:

$$
t_{c, 0}=\frac{\rho_{p} \operatorname{Pr}\left(D_{i}^{2}-D_{r}^{2}\right)}{4 \mu \ln (1+\mathrm{B}) \mathrm{Sh}}
$$


The motion of the combustion volume boundary is linked to droplet diameter fluctuations and to the mean flow by [29]:

$$
\hat{r}_{c}=\frac{2 t_{c, 0} v_{p} D_{0}}{D_{i}^{2}-D_{r}^{2}} \hat{D}
$$

Fluctuations of the droplet diameter drive lifetime droplet oscillations, but also change the dynamics at which heat is released in the combustion volume. Linearization of Eq. (11) for the mass flow rate $\dot{m}_{D^{2}}$ yields an expression for the volumetric contribution to heat release rate fluctuations:

$$
\hat{\dot{q}}_{v \cdot c}=\dot{q}_{0}\left(\frac{\mathrm{Sh}_{0}-2}{2 \mathrm{Sh}_{0}} \frac{\delta u_{p, 0}}{\left|\delta \mathbf{u}_{\mathbf{p}}\right|_{0}^{2}}\left(\hat{u}_{p}-\hat{u}\right)+\left(1+\frac{\mathrm{Sh}_{0}-2}{2 \mathrm{Sh}_{0}}\right) \frac{\hat{D}}{D_{0}}\right)
$$

This expression is an extension of Eq. 27) by considering that the flow not only alters the droplet velocity, but also the droplet diameter.

Summing the volumetric and boundary contributions to heat release disturbances yields:

$$
\frac{\hat{\dot{q}}}{\dot{q}_{0}}=\frac{\mathrm{Sh}_{0}-2}{2 \mathrm{Sh}_{0}} \frac{\delta u_{p, 0}}{\left|\delta \mathbf{u}_{\mathbf{p}}\right|_{0}^{2}}\left(\hat{u}_{p}-\hat{u}\right)+\left(1+\frac{\mathrm{Sh}_{0}-2}{2 \mathrm{Sh}_{0}}\right) \frac{\hat{D}}{D_{0}}-\frac{\dot{q}_{D^{2}, 0}}{\dot{q}_{0}} \frac{2\left(1-\left(\frac{r-r_{c, 0}}{\left|\hat{r}_{c}\right|}\right)^{2}\right)^{1 / 2}}{\pi\left|\hat{r}_{c}\right|} \hat{r}_{c}
$$

Heat release rate fluctuations now depend on the mean flow, droplet and gas velocity fluctuations and droplet diameter fluctuations. These disturbances can be expressed as a function of the axial gas velocity disturbances $\hat{u}$ and the mean flow properties only. To close the model Eq. (40), it is necessary to express the diameter and droplet velocity fluctuations $\left(\hat{D}\right.$ and $\left.\hat{u}_{p}\right)$ as functions of the mean flow and gas velocity fluctuations $\hat{u}$.

The governing transport equations for droplet diameter and droplet axial velocity disturbances are derived as follows. In subsection IV.A. all the advection terms in Eq. (30) were neglected. However, as aluminum combustion takes place in the acoustic boundary layer (Fig. 5), the radial gradients of the droplet and gas velocity fluctuations $\left(\partial u_{1} / \partial r\right.$ and $\left.\partial u_{p, 1} / \partial r\right)$ can not be neglected. This leads to a new transport equation for droplet velocity fluctuations which is a simplification of Eq. (30) by only retaining the radial advection term and the drag characteristic time fluctuations:

$$
\frac{\partial u_{p, 1}}{\partial t}+v_{p} \frac{\partial u_{p, 1}}{\partial r}=-\frac{\delta u_{p, 1}}{\tau_{v, 0}}+\frac{\delta u_{p, 0}}{\tau_{v, 0}^{2}} \tau_{v, 1}
$$

A linearization of $\tau_{v}$ given by Eq. 29] yields:

$$
\frac{\tau_{v, 1}}{\tau_{v, 0}}=\left(2-C_{R e}\right) \frac{D_{1}}{D_{0}}-C_{R e} \frac{\delta u_{p, 0}}{\left|\delta \mathbf{u}_{\mathbf{p}, \mathbf{0}}\right|_{0}^{2}}\left(u_{p, 1}-u_{1}\right)
$$

in which $C_{R e}$ is depending on the mean particle Reynolds number $R e_{p, 0}$ (Eq. (15)):

$$
C_{R e}=\frac{0.10305 R e_{p, 0}}{1+0.15 R e_{p, 0}}
$$

Combining the transport equations Eqs. [5] - 8 for the mass of the droplet phase $\alpha_{p} \rho_{p}$ and for the number $N_{p}$ of particles per unit volume with the definition of the droplet diameter $D$ given by Eq. (10) yields a transport equation for the droplet diameter in an Eulerian framework:

$$
\frac{\partial D}{\partial t}+\mathbf{u}_{\mathbf{p}} \cdot \nabla D=-\frac{2 \mu \ln (1+\mathrm{B}) \mathrm{Sh}}{\operatorname{Pr} \rho_{p} D}
$$

Assuming that (1) the combustion volume thickness remains small with quasi-1D droplet trajectories as in Fig. 3. (2) the rate of droplet injection at the propellant surface is uniform along the axial direction, (3) the acoustic mode is locked to the first longitudinal acoustic mode of the motor and (4) the droplet diameter is regressing along its trajectory (the radial derivative of $D_{1}$ is non-negligible), all the advection terms can be neglected except the radial term in the linearization of Eq. (44):

$$
\frac{\partial D_{1}}{\partial t}+v_{p} \frac{\partial D_{1}}{\partial r}=-\frac{2 \mu \ln \left(1+\mathrm{B}_{0}\right) \mathrm{Sh}_{0}}{\operatorname{Pr} \rho_{p} D_{0}}\left(\frac{\mathrm{Sh}}{D}\right)_{1}
$$




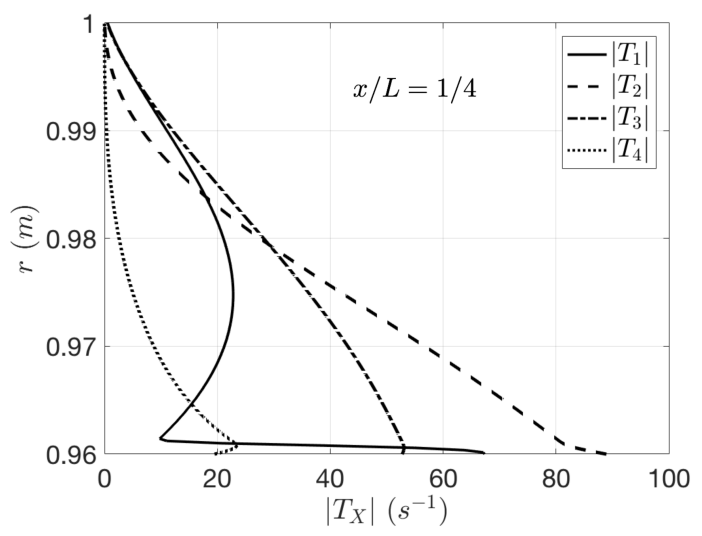

(a) $x / L=1 / 4$

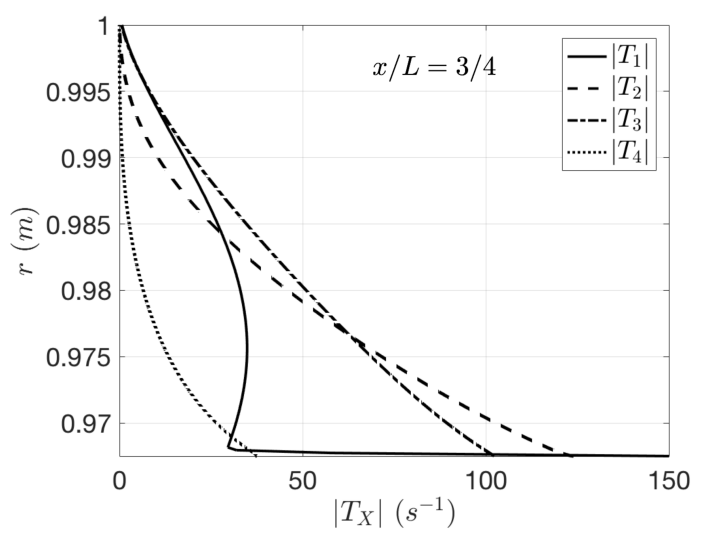

(b) $x / L=3 / 4$

Fig. 8 Comparison between the modulus of the different terms from Eq. (49), at $x / L=1 / 4$ and $x / L=3 / 4$, in the combustion zone calculated by the numerical flow solver.

with:

$$
\left(\frac{\mathrm{Sh}}{D}\right)_{1}=\frac{\mathrm{Sh}_{0}-2}{2 \mathrm{Sh}_{0}} \frac{\delta u_{p, 0}\left(u_{p, 1}-u_{1}\right)}{\left|\delta u_{p}\right|_{0}^{2}}-\frac{\mathrm{Sh}_{0}+2}{2 \mathrm{Sh}_{0}} \frac{D_{1}}{D_{0}}
$$

The assumptions (1), (2), (3) and (4) are realistic in usual solid rocket motors. In the Fourier space, Eq. (41) yields a first order differential equation, in $r$, for $\hat{u}_{p}$ :

$$
\frac{\partial \hat{u}_{p}}{\partial r}+\frac{\hat{u}_{p}}{v_{p} \tau_{v, 0}}\left(i \omega \tau_{v, 0}+1+C_{R e} \frac{\delta u_{p, 0}^{2}}{\left|\delta \mathbf{u}_{\mathbf{p}}\right|_{0}^{2}}\right)=\frac{\hat{u}}{v_{p} \tau_{v, 0}}\left(1+C_{R e} \frac{\delta u_{p, 0}^{2}}{\left|\delta \mathbf{u}_{\mathbf{p}}\right|_{0}^{2}}\right)+\frac{\hat{D} \delta u_{p, 0}}{D_{0} v_{p} \tau_{v, 0}}\left(2-C_{R e}\right)
$$

This equation depends on droplet diameter fluctuations $\hat{D}$ which are the solution of the Fourier transform of Eq. (45):

$$
\frac{\partial \hat{D}}{\partial r}+\hat{D}\left(\frac{i \omega}{v_{p}}-\frac{\mu \ln (1+\mathrm{B})\left(S h_{0}+2\right)}{v_{p} \operatorname{Pr} \rho_{p} D_{0}^{2}}\right)=-\frac{\mu \ln (1+\mathrm{B})\left(S h_{0}-2\right)}{v_{p} \operatorname{Pr} \rho_{p} D_{0}\left|\delta \mathbf{u}_{\mathbf{p}}\right|_{0}^{2} / \delta u_{p, 0}}\left(\hat{u}_{p}-\hat{u}\right)
$$

The expressions (47) and (48) constitute a system of two coupled ordinary differential equations for the droplet velocity and droplet diameter fluctuations. This equation system has no analytical solution. It can be resolved numerically or further simplified in an attempt to find analytical solutions. To derive analytical solutions, a term in the equation system (47) and (48) needs to be removed. The most appropriate equation to reduce is Eq. 477:

$$
\underbrace{\frac{\partial \hat{u}_{p}}{\partial r}}_{T_{1}}+\underbrace{\frac{\hat{u}_{p}}{v_{p} \tau_{v, 0}}\left(i \omega \tau_{v, 0}+1+C_{R e} \frac{\delta u_{p, 0}^{2}}{\left|\delta \mathbf{u}_{\mathbf{p}}\right|_{0}^{2}}\right)}_{T_{2}}=\underbrace{\frac{\hat{u}}{v_{p} \tau_{v, 0}}\left(1+C_{R e} \frac{\delta u_{p, 0}^{2}}{\left|\delta \mathbf{u}_{\mathbf{p}}\right|_{0}^{2}}\right)}_{T_{3}}+\underbrace{\frac{\hat{D} \delta u_{p, 0}}{D_{0} v_{p} \tau_{v, 0}}\left(2-C_{R e}\right)}_{T_{4}}
$$

where $T_{1}, T_{2}, T_{3}$ and $T_{4}$ are the four terms from Eq. 49p. The modulus of these terms calculated by direct numerical flow simulations are plotted in Fig. 8 in the combustion zone at $x / L=1 / 4$ and $x / L=3 / 4$, where the thermo-acoustic coupling is the highest (Fig. (4). This figure shows that the advection term $T_{1}$ cannot be neglected as expected and that $T_{4}$ associated to droplet diameter fluctuations is smaller than the other contributions. Neglecting $T_{4}$ leads to an analytical solution of the ordinary differential system Eqs. (47) and (48). In that case, Eq. (47) is reduced to:

$$
\frac{\partial \hat{u}_{p}}{\partial r}+\frac{\hat{u}_{p}}{v_{p} \tau_{v, 0}}\left(i \omega \tau_{v, 0}+1+C_{R e} \frac{\delta u_{p, 0}^{2}}{\left|\delta \mathbf{u}_{\mathbf{p}}\right|_{0}^{2}}\right)=\frac{\hat{u}}{v_{p} \tau_{v, 0}}\left(1+C_{R e} \frac{\delta u_{p, 0}^{2}}{\left|\delta \mathbf{u}_{\mathbf{p}}\right|_{0}^{2}}\right)
$$

This expression does not depend on $\hat{D}$. In our analytical approach, we do not consider radial velocity, density and temperature fluctuations, the injected mass flow rate at the solid propellant boundary $(r / R=1)$ is constant and the axial 


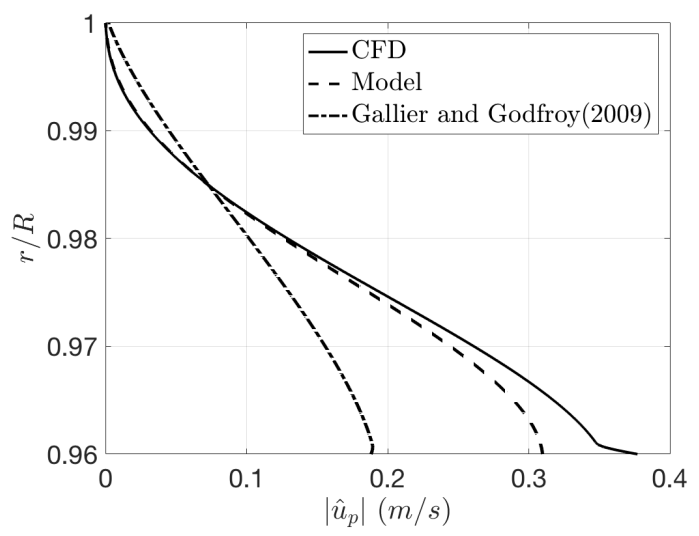

(a) Droplet velocity fluctuation modulus

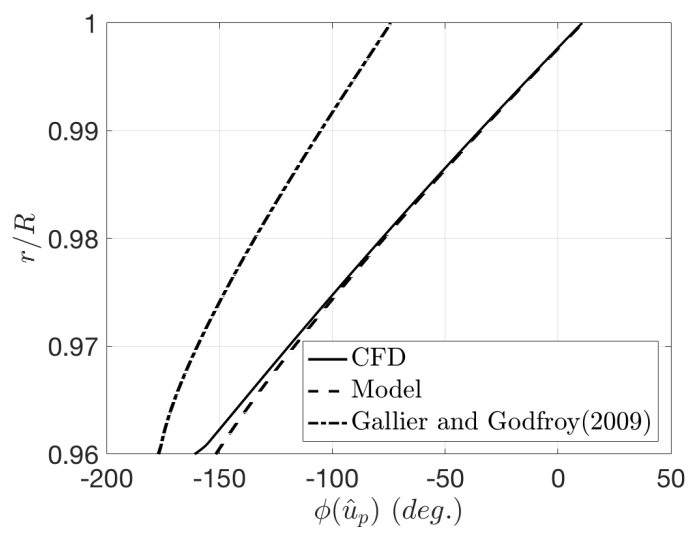

(b) Droplet velocity fluctuation phase lag

Fig. 9 Radial profiles of droplet velocity fluctuation modulus and phase lag in the aluminum combustion zone at $x / L=1 / 4$. Comparison between numerical flow simulations (CFD), the analytical model Eq. (51) developed in this study (Model) and the model developed by Gallier and Godfroy (subsection[IV.A, [27]). The phase lag is expressed with respect to the acoustic pressure.

velocity fluctuations at the injection is equal to zero $(\hat{u}(r=R)=0)$. So, droplet velocity and diameter fluctuations at the injection are therefore equal to zero $\left(\hat{u}_{p}(r=R)=0\right.$ and $\left.\hat{D}(r=R)=0\right)$. The solution of Eq. (50) for $\hat{u}_{p}(r=R)=0$ is:

$$
\hat{u}_{p}=\int_{R}^{r} \frac{\hat{u}}{v_{p} \tau_{v, 0}}\left(1+C_{R e} \frac{\delta u_{p, 0}^{2}}{\left|\delta \mathbf{u}_{\mathbf{p}}\right|_{0}^{2}}\right) e^{\int_{r}^{r^{\prime}}\left(i \omega \tau_{v, 0}+1+C_{R e} \frac{\delta u_{p, 0}^{2}}{\left|\delta \mathbf{u}_{p}\right|_{0}^{2}}\right) \frac{d r^{\prime \prime}}{v_{p} \tau_{v, 0}}} d r^{\prime}
$$

Let us define the transfer function $\mathcal{F}_{p}=\hat{u}_{p} / \hat{u}$. This transfer function is linear and depends on the structure of the acoustic boundary layer and on the history of the fuel droplets during their transport, from their injection surface to their current radial position $r$. Equation (48) can now be resolved by substitution of the solution Eq. (51) for $\hat{D}(r=R)=0$ :

$$
\hat{D}=-\int_{R}^{r} \hat{u} \frac{\mu \ln (1+\mathrm{B})\left(\mathrm{Sh}_{0}-2\right)}{v_{p} \operatorname{Pr} \rho_{p} D_{0}\left|\delta \mathbf{u}_{\mathbf{p}}\right|_{0}^{2} / \delta u_{p, 0}}\left(\mathcal{F}_{p}-1\right) e^{\int_{r}^{r^{\prime}}\left(\frac{i \omega}{v_{p}}-\frac{\mu \ln (1+\mathrm{B})\left(\mathrm{Sh}_{0}+2\right)}{v_{p} \operatorname{Pr} \rho_{p} D_{0}^{2}}\right) d r^{\prime \prime}} d r^{\prime}
$$

The expressions Eq. (51) for the droplet velocity fluctuations $\hat{u}_{p}$ and Eq. (52) for the droplet diameter fluctuations $\hat{D}$ can now be compared to numerical simulation results. The mean flow quantities and the gas velocity fluctuations $\hat{u}$ are again taken from the flow simulations to evaluate these expressions.

The modulus and phase lag of the droplet velocity fluctuations $\hat{u}_{p}$ calculated with Eq. (51), with Eq. (32) from Gallier and Godfroy model and from direct numerical flow simulations are compared in Fig. 9 in the aluminum combustion zone at the quarter of the chamber $x / L=1 / 4$. The phase lag is expressed with respect to the acoustic pressure. The new model Eq. (51) fits better the numerical flow results than Eq. (32), justifying to consider the advection term in Eq. (50) due to the presence of the acoustic boundary layer and fluctuations of the drag characteristic time in response to gas and droplet velocity disturbances. A slight difference is observed at the end of the combustion process for $0.96 \leq r / R \leq 0.98$ between this new model and results from the simulations because the contribution from droplet diameter fluctuations have been neglected in the droplet velocity fluctuation model $\left(T_{4}\right.$ in Eq. (49)). The same observations can be done at other axial positions in the SRM chamber.

There has been so far no model developed for droplet diameter disturbances $\hat{D}$. It is worth recalling that Eq. (52) depends on Eq. (51) for the droplet velocity fluctuations. Equation (52) is compared to numerical flow results in Fig. 10 for the modulus and the phase lag at the quarter of the tube $x / L=1 / 4$ in the aluminum combustion zone. The model yields very close results to the numerical flow simulations over the entire volume of the combustion zone, even at the end of the combustion process. This proves the low impact of neglecting droplet diameter fluctuations in the droplet velocity fluctuation model by removing the term $T_{4}$ in Eq. (49). In phase lag, close to the injection for $0.995 \leq r / R \leq 1$, the model does not fit well to CFD simulations, certainly because the radial velocity fluctuations have been neglected 


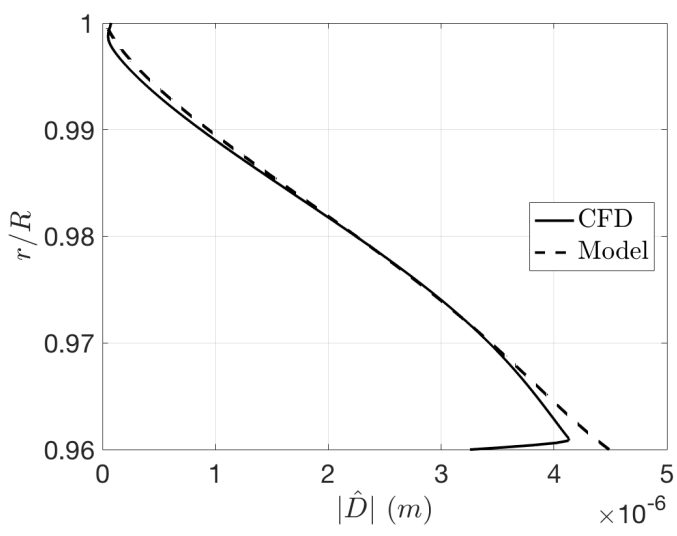

(a) Diameter fluctuation modulus

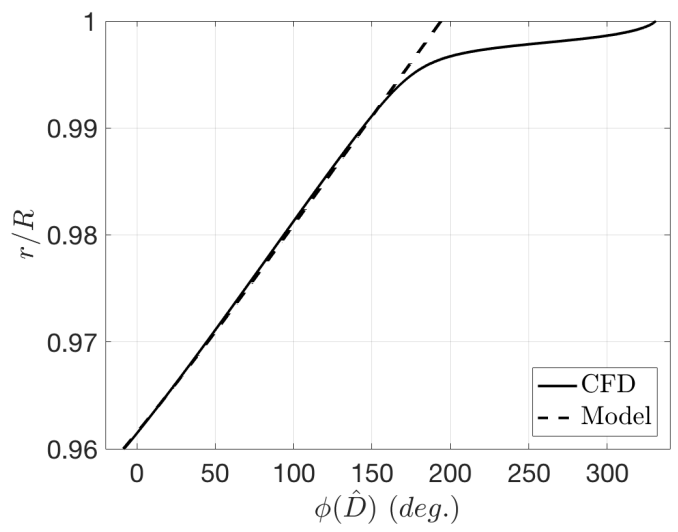

(b) Diameter fluctuation phase lag

Fig. 10 Radial profiles of droplet diameter fluctuation modulus and phase lag in the aluminum combustion zone at $x / L=1 / 4$. Comparison between numerical flow simulations (CFD) and the analytical model Eq. (52) developed in this study (Model). The phase lag is expressed with respect to the acoustic pressure.

$\left(v_{p}=v_{p, 0}\right)$ in Eq. [52], however, as the diameter modulus is close to zero, these discrepancies can be finally neglected. This model yields similar results at other axial positions in the SRM.

The new expression for the heat release rate fluctuations $\hat{\dot{q}}$ is recalled here:

$$
\begin{gathered}
\frac{\hat{\dot{q}}}{\dot{q}_{0}}=\frac{\mathrm{Sh}_{0}-2}{2 \mathrm{Sh}_{0}} \frac{\delta u_{p, 0}}{\left|\delta \mathbf{u}_{\mathbf{p}}\right|_{0}^{2}}\left(\hat{u}_{p}-\hat{u}\right)+\left(1+\frac{\mathrm{Sh}_{0}-2}{2 \mathrm{Sh}_{0}}\right) \frac{\hat{D}}{D_{0}}-\frac{\dot{q}_{D^{2}, 0}}{\dot{q}_{0}} \frac{2\left(1-\left(\frac{r-r_{c, 0}}{\left|\hat{r}_{c}\right|}\right)^{2}\right)^{1 / 2}}{\pi\left|\hat{r}_{c}\right|} \hat{r}_{c} \\
\hat{r}_{c}=\frac{2 t_{c, 0} v_{p} D_{0}}{D_{i}^{2}-D_{r}^{2}} \hat{D} \\
\hat{u}_{p}=\int_{R}^{r} \frac{\hat{u}}{v_{p} \tau_{v, 0}}\left(1+C_{R e} \frac{\delta u_{p, 0}^{2}}{\left|\delta \mathbf{u}_{\mathbf{p}}\right|_{0}^{2}}\right) e^{\int_{r}^{r^{\prime}}\left(i \omega \tau_{v, 0}+1+C_{R e} e \frac{\delta u_{p, 0}^{2}}{\left|\delta \mathbf{u}_{p}\right|_{0}^{2}}\right) \frac{d r^{\prime \prime}}{v_{p} \tau_{v, 0}}} d r^{\prime} \\
\hat{D}=-\int_{R}^{r} \hat{u} \frac{\mu \ln (1+\mathrm{B})\left(\mathrm{Sh}_{0}-2\right)}{v_{p} \operatorname{Pr} \rho_{p} D_{0}\left|\delta \mathbf{u}_{\mathbf{p}}\right|_{0}^{2} / \delta u_{p, 0}}\left(\mathcal{F}_{p}-1\right) e^{\int_{r}^{r^{\prime}}\left(\frac{i \omega}{v_{p}}-\frac{\mu \ln (1+\mathrm{B})\left(\mathrm{Sh}_{0}+2\right)}{v_{p} \operatorname{Pr} \rho_{p} D_{0}^{2}}\right) d r^{\prime \prime}} d r^{\prime}
\end{gathered}
$$

with $\mathcal{F}_{p}=\hat{u}_{p} / \hat{u}$. This model allows to express the heat release perturbations from the burning aluminum droplets as a function of the mean flow properties and of the axial gas velocity fluctuations $\hat{u}$. To compare this model and the heat release rate fluctuations calculated by the numerical flow solver, the mean flow and the axial gas velocity fluctuations $\hat{u}$ are extracted from the simulations.

Figures 11 and 12 compare the modulus and phase lag of the heat release rate disturbances given by the new model, by the model from Gallier and Godfroy (subsection IV.A. [27]) and by the numerical flow simulation. Results are plotted in the aluminum combustion zone at $x / L=1 / 4$ and $x / L=3 / 4$ that correspond to the maximum and minimum for the local Rayleigh source term $\mathcal{S}$ shown in Fig. 4 .

The new model is very close to numerical flow simulation results at both axial positions and better fits than the model from Gallier and Godfroy. In the combustion volume, no significant differences can be observed allowing to validate the assumption made on $T_{4}$ in Eq. (49) and the expression derived to model the volumetric contribution $\hat{\dot{q}}_{v . c .}$. Also, the boundary flapping motion $\hat{r}_{c}$ is well reproduced and the heat release rate modulus and phase lag are also very close to the numerical flow results. The heat release rate fluctuations in the flapping zone essentially depend on $\hat{\dot{q}}_{\text {b.c. }}$, which are directly linked to the modulus of the flapping motion $\left|\hat{r}_{c}\right|$ and to the pressure amplitude $\hat{\eta}$ pulsation [29]. In the expression for $\hat{\dot{q}}_{\text {b.c. }}$, the flapping motion has been assumed to be symmetrical and comparisons with numerical flow simulations allow to validate this assumption in the linear domain. 


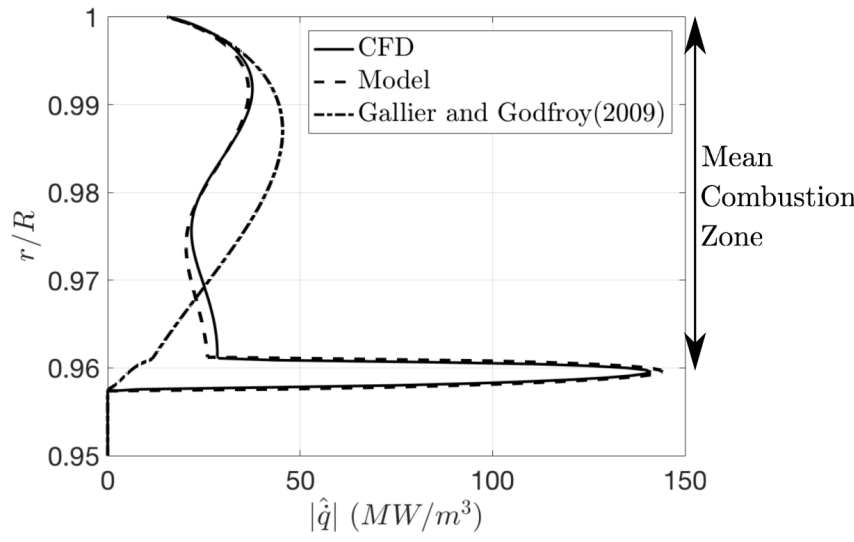

(a) Heat release rate fluctuation modulus at $x / L=1 / 4$

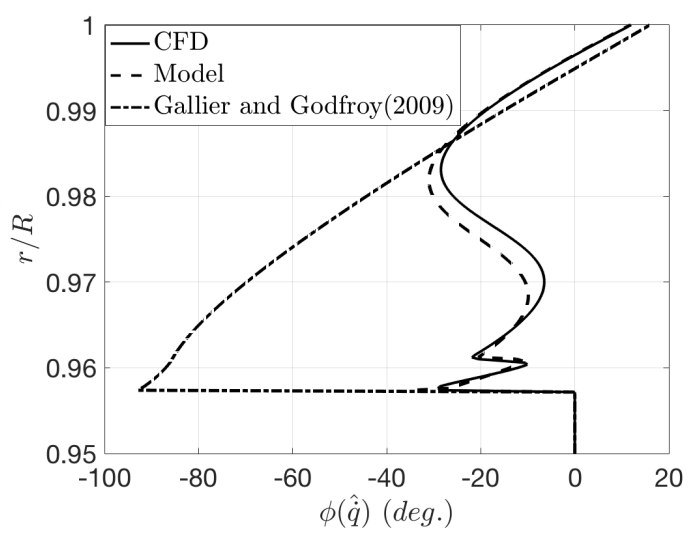

(b) Heat release rate fluctuation phase lag at $x / L=1 / 4$

Fig. 11 Radial profiles of modulus and phase lag of the heat release rate fluctuations in the aluminum combustion zone at $x / L=1 / 4$. Comparison between numerical flow simulations (CFD), the analytical model Eq. (53) developed in this study (Model) and the model from Gallier and Godfroy [27]. The phase lag is expressed with respect to the acoustic pressure.

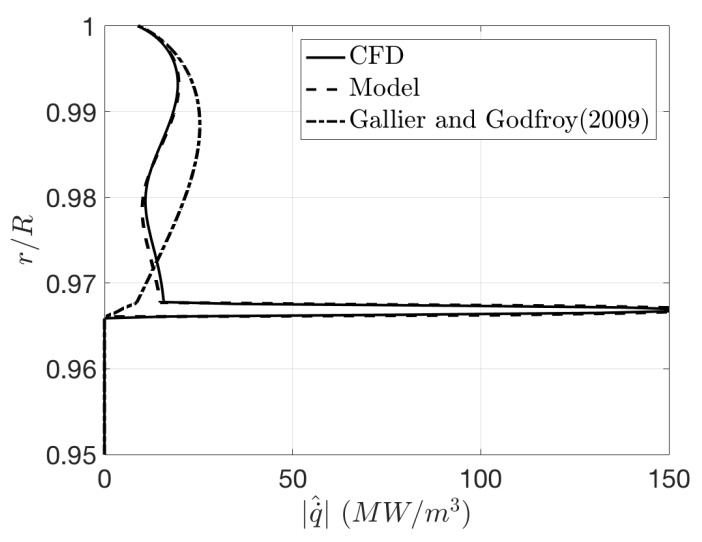

(a) Heat release rate fluctuation modulus at $x / L=3 / 4$

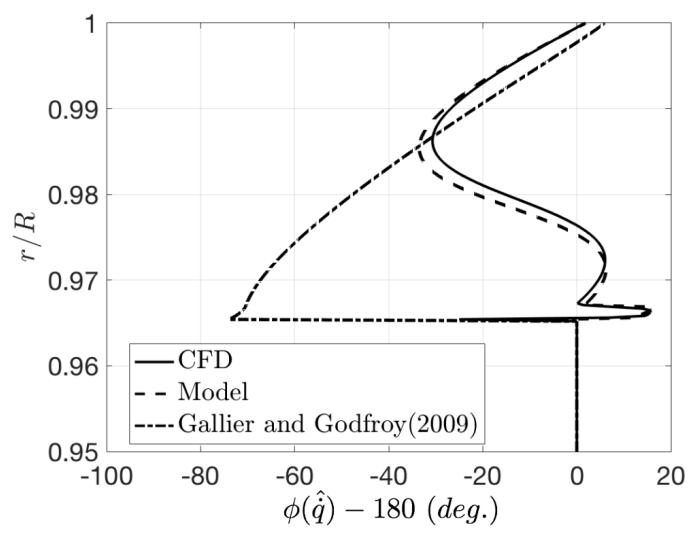

(b) Heat release rate fluctuation phase lag at $x / L=3 / 4$

Fig. 12 Radial profiles of modulus and phase lag of the heat release rate fluctuations in the aluminum combustion zone at $x / L=3 / 4$. Comparison between numerical flow simulations (CFD), the analytical model Eq. (53) developed in this study (Model) and the model from Gallier and Godfroy [27]. The phase lag is expressed with respect to the acoustic pressure.

The same observations could be done at other axial positions through the motor. The slight differences which can be observed between the model and the simulation results are due to the choices of physical reductions in the analytical model (assumption $T_{4}, \hat{v}=0, \hat{v}_{p}=0, \hat{T}_{g}=0, \hat{\rho}_{g}=0, \hat{N}_{p}=0, \frac{\partial}{\partial x}=0$ ).

\section{Axial gas velocity model within the aluminum combustion zone}

In the previous section, heat release rate fluctuations were derived as a function of the mean flow properties and of axial gas velocity fluctuations $\hat{u}$. These latter quantities were both extracted from numerical flow simulations. To derive an analytical model for $\hat{\dot{q}}$ which do not need an unsteady two-phase flow simulation, for example to predict the stability of a SRM by a low order tool, it can be useful to give a model for the axial velocity fluctuations $\hat{u}$ taking place in the aluminum combustion zone.

Flandro et al. [64] derived an expression for this velocity in the acoustic boundary layer of an isentropic and gaseous 


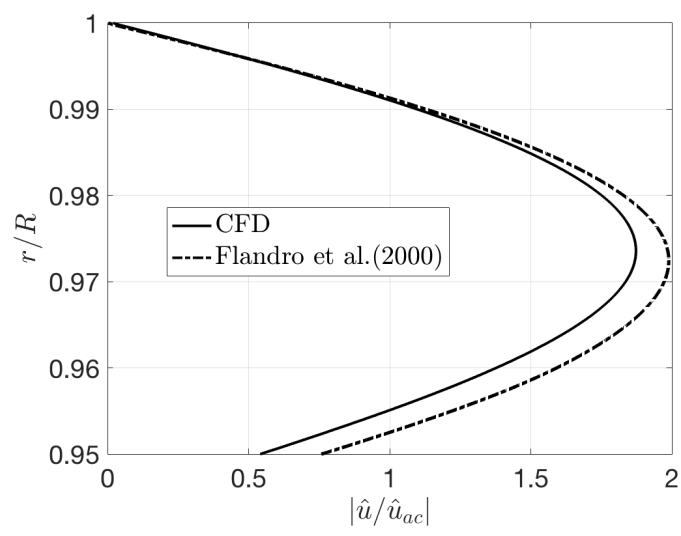

(a) Axial gas velocity fluctuation modulus

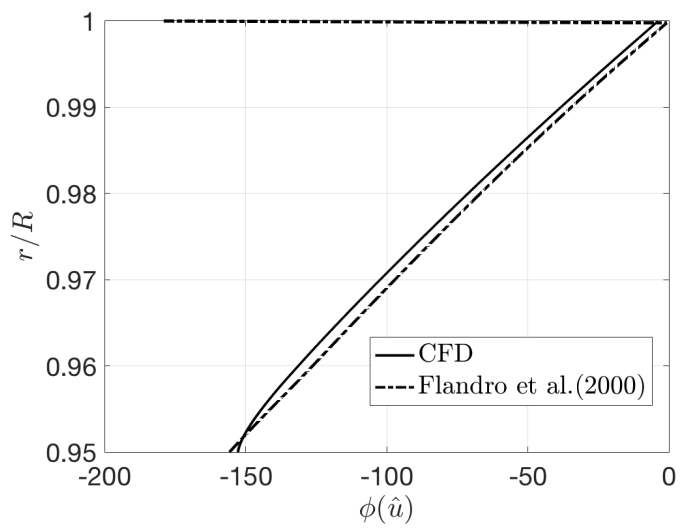

(b) Axial gas velocity fluctuation phase lag

Fig. 13 Radial profiles of modulus and phase lag of the axial gas velocity fluctuations $\hat{u}$ in the aluminum combustion zone at $x / L=1 / 4$. Comparison between numerical flow simulations (CFD) and the model by Flandro [64]. The phase lag is expressed with respect to the acoustic pressure and the modulus is normalized by the acoustic velocity fluctuations $\hat{u}_{a c}$ which is invariant in the radial direction.

mean flow. In this model, the unsteady velocity can be broken up into acoustic and rotational parts:

$$
\hat{u}=\hat{u}_{a c}+\hat{u}_{r o t}
$$

where the acoustic component is assumed to correspond to the first longitudinal mode of a closed-closed chamber cavity:

$$
\hat{u}_{a c}=-\frac{i \hat{\eta}}{a_{0} \rho} \sin (k x) \quad k=\frac{\omega}{a_{0}}
$$

with $k$ the wavelength, $a_{0}$ the speed of sound, $\rho=\alpha_{p} \rho_{p}+\rho_{g}$ the density of a two-phase flow and $\hat{\eta}$ the pressure amplitude. The rotational contribution in Eq. 57] is given by:

$$
\hat{u}_{\text {rot }}=-\frac{i \hat{\eta}}{a_{0} \rho}\left(\beta \frac{r}{R} \sin (k x \sin \Theta) e^{\Phi+i \frac{S}{\pi} \ln \left(\tan \frac{\Theta}{2}\right)}\right)
$$

with $\Phi$ a complex expression given in [64], $\Theta=\frac{\pi}{2}(r / R)^{2}$ and $\beta$ is equal to:

$$
\beta=\frac{C_{\beta}}{S}\left(\frac{r}{R} \sin \Theta+i \frac{\xi R}{\operatorname{Sr} \sin (\Theta)}\right)
$$

where $R$ is the chamber radius, $S$ is the Strouhal number, $\xi$ a viscous parameter and $C_{\beta}$ a constant of integration which are given in [64]:

$$
S=\frac{\omega R}{v_{i}} \quad \xi=\frac{S^{2}}{R e_{i}} \quad C_{\beta}=-\frac{S^{3}\left(\left(S^{2}+\xi\right)-i S \xi\right)}{\left(S^{2}+\xi\right)^{2}+(S \xi)^{2}}
$$

with $v_{i}$ the gas injection velocity and $R e_{i}=\frac{\rho v_{i} R}{\mu}$ the injection Reynolds number, $\rho$ the mixture density and $\mu$ the dynamic viscosity.

Radial profiles of the modulus and phase lag of the axial gas velocity $\hat{u}$ in the aluminum combustion zone at $x / L=1 / 4$ are plotted in Fig. 13. A comparison is made between the model Eqs. (58) and (59) and direct flow simulations. Slight differences can be observed for the modulus of the axial velocity fluctuation $\hat{u}$ between the Flandro model and numerical flow results due to deviation from a perfectly isentropic and single phase flow as assumed in the analytical model. For the phase lag, direct flow simulations and analytical results are very close. These comparisons yield similar results at all axial locations in the SRM. So the entropic noise, induced by the droplets and the heat release rate, on the velocity fluctuations $\hat{u}$ can be neglected. 


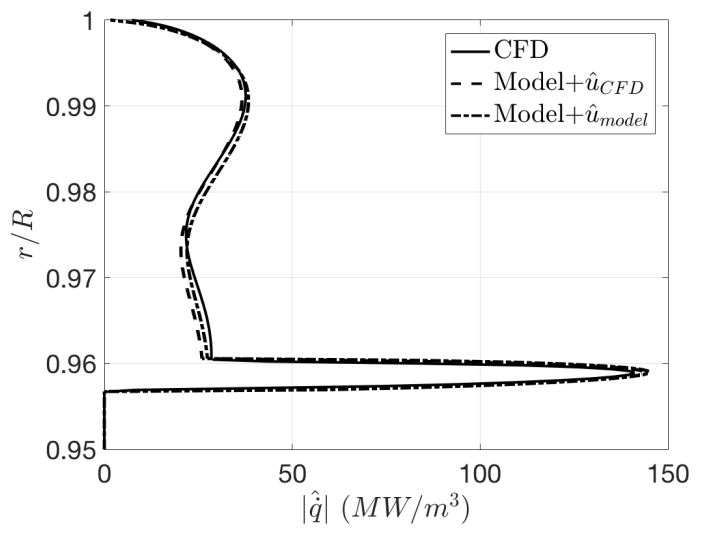

Fig. 14 Radial profile of modulus of the heat release rate fluctuations $\hat{q}$ in the aluminum combustion zone at $x / L=1 / 4$. Comparison between numerical flow simulations (CFD), the model Eq. (53) with velocity fluctuations extracted from CFD and the model Eq. (53) with velocity fluctuations given by the Flandro model Eq. 57].

A last comparison is made by substituting the axial velocity fluctuations calculated with the numerical flow simulations in the heat release fluctuation model Eq. (53) by the Flandro model Eqs. (58) and (59). The results for the modulus of the heat release rate fluctuations $\hat{\dot{q}}$ given by the numerical flow solver are compared in Fig. 14 to the model Eq. (53) with the velocity fluctuations extracted from numerical flow simulations and with velocity fluctuations modeled by the Flandro model at the quarter of the tube $x / L=1 / 4$, in the aluminum combustion zone. In the latter case, the heat release rate fluctuations are expressed only as a function of the mean flow properties, the forcing angular frequency $\omega$ and the pressure amplitude $\hat{\eta}$. Results with this fully analytical model in Fig. 14 are found to be very close to the other results. The same observations can be made for the phase lag signal and at other axial positions within the SRM.

These comparisons indicate that small heat release rate disturbances $\hat{\dot{q}}$ are well predicted by the analytical model provided the mean flow properties and the modal distribution are known through the SRM. This model may in turn be used to conduct a linear stability analysis for different operating conditions of the SRM.

\section{Conclusion}

The way acoustic perturbations lead to heat release rate disturbances originating from aluminum droplet combustion has been investigated numerically and theoretically in a generic SRM.

Numerical flow simulations have been used to analyze the origin of thermo-acoustic instabilities driven by droplet aluminum combustion by carefully avoiding other coupling mechanisms linked to hydrodynamic instabilities (no turbulence, cylindrical geometry, no large vortical structures). These simulations are based on an Eulerian framework, for the gaseous and disperse phases, in which the combustion of disperse droplets is modeled by the $\mathrm{D}^{2}$ law which is abruptly quenched when the droplet diameter falls below a threshold level to model the formation of oxide residues.

Analysis of the heat release rate and the Rayleigh source term distributions through the motor chamber reveals two contributions to pressure oscillations: (1) heat release rate fluctuations produced within the volume of the reactive droplet cloud and (2) heat release rate disturbances originating from the flapping boundary of the droplet cloud. The volumetric contribution to heat release fluctuations results from the individual response of each aluminum droplet to the unsteady flow which is synchronized by the acoustic forcing. This flows produces unsteady drag and convection altering the droplet velocity and droplet diameter leading in turn to disturbances of the droplet fuel consumption rate. The second contribution is due to oscillations of the droplet lifetime induced by the history of the droplet dynamics in the acoustically perturbed flow. These fluctuations lead to a motion of the boundary of the combustion volume associated with large heat release fluctuations.

Analytical models were developed for these two contributions to heat release fluctuations from aluminum droplets in acoustically forced flows and were compared to numerical flow results. These models include both a description of droplet diameter fluctuations and droplet velocity fluctuations. They allow to determine the heat release disturbances originating from the combustion volume and the motion of the boundary.

Different levels of approximations were made to get an hybrid solution combining numerical and analytical results 
or fully analytical results by only specifying the structure of the mean flow and the modal characteristics and get reliable estimates of the heat release rate fluctuations through the SRM. These models well reproduce the dynamics observed in the numerical flow simulations.

This local heat release rate fluctuation model is well suited to rapidly conduct a linear stability analysis of the system dynamics and may be used to ease the prediction of thermo-acoustic instabilities in solid rocket motors driven by aluminum droplet combustion and better understand these dynamical phenomena without requiring intensive numerical unsteady two-phase flow simulations.

\section{Acknowledgments}

This work is cofunded by the French space agency Centre National d'Etudes Spatiales (CNES) and ArianeGroup. The authors would like to thank Julien Pichillou and Nathalie Cesco for their support.

\section{References}

[1] Price, E. W., "Solid Rocket Combustion Instability-An American Historical Account," Nonsteady Burning and Combustion Stability of Solid Propellants, edited by L. De Luca, E. W. Price, and M. Summerfield, Vol. 143, Chapter 1, Progress in Astronautics and Aeronautics, AIAA Washington, DC, 1992, pp. 1-16.

[2] Culick, F., "Unsteady Motions in Combustion Chambers for Propulsion Systems," AGARDograph, NATO/RTO-AG-AVT-039, 2006.

[3] Fabignon, Y., Dupays, J., Avalon, G., Vuillot, F., Lupoglazoff, N., Casalis, G., and Prévost, M., "Instabilities and Pressure Oscillations in Solid Rocket Motors," Aerospace Science and Technology, Vol. 7, No. 3, 2003, pp. 191-200, doi: $10.1016 / \mathrm{S} 1270-9638(02) 01194-\mathrm{X}$

[4] Orlandi, O., Plaud, M., Godfroy, F., Larrieu, S., and Cesco, N., "Aluminium Droplets Combustion and SRM Instabilities," 7th European Conference for Aeronautics and Space Sciences, Milan (Italy), EUCASS Paper 2017-532, July 2017.

[5] Blomshield, F., "Historical Perspective Of Combustion Instability In Motors-Case Studies," AIAA Paper 2001-3875, July 2001.

[6] Anthoine, J., "Solid Propellant Pressure Oscillations," VKI / STO-AVT-206 Lecture Series on Fluid Dynamics Associated to Launcher Developers, von Kármán Inst., Rhode-Saint-Genèse, Belgium, April 2013.

[7] Culick, F. E. C. and Yang, V., "Prediction of the Stability of Unsteady Motions in Solid Propellant Rocket Motors," Nonsteady Burning and Combustion Stability of Solid Propellants, edited by L. De Luca, E. W. Price, and M. Summerfield, Vol. 143, Chapter 18, Progress in Astronautics and Aeronautics, AIAA Washington, DC, 1992, pp. 719-779.

[8] Vuillot, F. and Lupoglazoff, N., "Combustion and Turbulent Flow Effects in 2-D Unsteady Navier-Stokes Simulations of Oscillatory Rocket Motors,” AIAA Paper 1996-884, January 1996.

[9] Gallier, S., Prevost, M., Hijlkema, J., and Roumy, M., "Effects of Cavity on Thrust Oscillations in Subscale Solid Rocket Motors," AIAA Paper 2009-5253, August 2009.

[10] Hirschberg, L., Schuller, T., Collinet, J., Schram, C., and Hirschberg, A., "Analytical Model for the Prediction of Pulsations in a Cold-Gas Scale-Model of a Solid Rocket Motor," Journal of Sound and Vibration, Vol. 419C, 2018, pp. 452-468, doi: $10.1016 / j . j s v .2018 .01 .025$

[11] Anthoine, J., Buchlin, J. M., and Hirschberg, A., "Effect of Nozzle Cavity on Resonance in Large SRM: Theoretical Modeling," Journal of Propulsion and Power, Vol. 18, No. 2, 2002, pp. 304-311, doi: $10.2514 / 2.5935$.

[12] Hirschberg, L., Schuller, T., Schram, C., Collinet, J., Yiao, M., and Hirschberg, A., "Interaction of a Vortex with a Contraction in a 2-Dimensional Channel: Incompressible Flow Prediction of Sound Pulse,” AIAA Paper 2017-3701, June 2017.

[13] Anthoine, J., Buchlin, J., and Hirschberg, A., "Theoretical Modelling of the Effect of the Nozzle Cavity Volume on the Resonance Level in Large Solid Rocket Motors,” AIAA Paper 2001-2102, May 2001.

[14] Brown, R. S., Dunlap, R., Young, S. W., and Waugh, R. C., "Vortex Shedding as a Source of Acoustic Energy in Segmented Solid Rockets," Journal of Spacecraft and Rockets, Vol. 18, No. 4, 1981, pp. 312-319, doi: $10.2514 / 3.57822$ 
[15] Matveev, K. I., "Reduced-Order Modeling of Vortex-Driven Excitation of Acoustic Modes," Acoustics Research Letters Online, Vol. 6, No. 1, 2005, pp. 14-19, doi: $10.1121 / 1.1815253$

[16] Vuillot, F., "Vortex-Shedding Phenomena in Solid Rocket Motors," Journal of Propulsion and Power, Vol. 11, No. 4, 1995, pp. 626-639, doi: $10.2514 / 3.23888$

[17] Fabignon, Y., Trubert, J. F., Lambert, D., Orlandi, O., and Dupays, J., "Combustion of Aluminum Particles in Solid Rocket Motors," AIAA Paper 2003-4807, July 2003.

[18] Babuk, V. A., Vasilyev, V. A., and Malakhov, M. S., "Condensed Combustion Products at the Burning Surface of Aluminized Solid Propellant," Journal of Propulsion and Power, Vol. 15, No. 6, 1999, pp. 783-793, doi: $10.2514 / 2.5497$.

[19] Devillers, R. W., Le Besnerais, G., Nugue, M., and Cesco, N., "Experimental Analysis of Solid-Propellant Surface during Combustion with Shadowgraphy Images: New Tools to Assist Aluminum-Agglomeration Modelling," 7th European Conference for Aeronautics and Space Sciences, Milan (Italy), EUCASS Paper 2017-327, July 2017.

[20] Temkin, S. and Dobbins, R. A., "Attenuation and Dispersion of Sound by Particulate-Relaxation Processes," The Journal of the Acoustical Society of America, Vol. 40, No. 2, 1966, pp. 317-324, doi: $10.1121 / 1.1910073$

[21] Karnesky, A. L. and Colucci, S. E., "Recent Occurrences of Combustion Instability in Solid Rocket Motors-An overview," Journal of Spacecraft and Rockets, Vol. 12, No. 1, 1975, pp. 33-38, doi: $10.2514 / 3.56948$

[22] Brooks, K. P. and Beckstead, M. W., "Dynamics of Aluminum Combustion," Journal of Propulsion and Power, Vol. 11, No. 4, 1995, pp. 769-780, doi: $10.2514 / 3.23902$

[23] Beckstead, M. W., “A Summary of Aluminum Combustion,” VKI special course on "internal aerodynamics in solid rocket propulsion”. Report number RTO-EN-023, von Kármán Inst., Rhode-Saint-Genèse, Belgium, May 2002.

[24] Raun, R. L. and Beckstead, M. W., "A numerical Model for Temperature Gradient and Particle Effects on Rijke Burner Oscillations," Combustion and Flame, Vol. 94, No. 1-2, 1993, pp. 1-24, doi: 10.1016/0010-2180(93)90015-U.

[25] Beckstead, M. and Butcher, A., “The Velocity Coupled T-Burner,” AIAA Paper 1974-200, Jan-Feb 1974.

[26] Gallier, S., Briquet, B., and Yiao, M., "Aluminum Combustion Can Drive Instabilities in Solid Rocket Motors: a T-Burner Study," submitted to Journal of Propulsion and Power.

[27] Gallier, S. and Godfroy, F., "Aluminum Combustion Driven Instabilities in Solid Rocket Motors," Journal of Propulsion and Power, Vol. 25, No. 2, 2009, pp. 509-521, doi: $10.2514 / 1.37664$

[28] Genot, A., Gallier, S., and Schuller, T., "A Numerical Analysis of the Aluminium Combustion Driven Instability in Solid Rocket Motors," 7th European Conference for Aeronautics and Space Sciences, Milan (Italy), EUCASS Paper 2017-064, July 2017.

[29] Genot, A., Gallier, S., and Schuller, T., "Thermo-Acoustic Instabilities Driven by Fuel Droplet Lifetime Oscillations," Proceedings of the Combustion Institute, submitted for publication, 2018.

[30] Gallier, S., Sibe, F., and Orlandi, O., "Combustion Response of an Aluminum Droplet Burning in Air," Proceedings of the Combustion Institute, Vol. 33, No. 2, 2011, pp. 1949-1956, doi: $10.1016 /$ j.proci.2010.05.046

[31] Dupays, J. and Vuillot, F., "Propagation of an Acoustic Wave in a Two-Phase Reactive Medium," AIAA Paper 1988-3696, July 1998.

[32] Dupays, J. and Vuillot, F., "Propagation of Acoustic Waves in a Two-Phase Vaporizing Mixture," Journal of Propulsion and Power, Vol. 18, No. 1, 2002, pp. 222-223, doi: $10.2514 / 2.5924$. 
[33] Priem, R. J. and Guentert, D. C., Combustion Instability Limits Determined by a Nonlinear Theory and a One-Dimensional Model, NASA TN D-1409, Washington, D.C, October 1962.

[34] Zhu, M., Dowling, A., and Bray, K., "Forced Oscillations in Combustors with Spray Atomizers," Journal of Engineering for Gas Turbines and Power, Vol. 124, No. 1, 2002, pp. 20-30, doi: $10.1115 / 1.1396841$

[35] Eckstein, J., Freitag, E., Hirsch, C., Sattelmayer, T., Von der Bank, R., and Schilling, T., "Forced Low-Frequency Spray Characteristics of a Generic Airblast Swirl Diffusion Burner," Journal of Engineering for Gas Turbines and Power, Vol. 127(2), 2005, pp. 301-306, doi: $10.1115 / 1.1789515$

[36] Giuliani, F., Gajan, P., Diers, O., and Ledoux, M., "Influence of Pulsed Entries on a Spray Generated by an Air-Blast Injection Device: An Experimental Analysis on Combustion Instability Processes in Aeroengines," Proceedings of the Combustion Institute, Vol. 29, No. 1, 2002, pp. 91-98, doi: 10.1016/S1540-7489(02)80016-5

[37] Carvalho, J. A., McQuay, M. Q., and Gotac, P. R., "The Interaction of Liquid Reacting Droplets with the Pulsating Flow in a Rijke-Tube Combustor," Combustion and Flame, Vol. 108, No. 1-2, 1997, pp. 87-103, doi: 10.1016/S0010-2180(96)00106-X

[38] Sujith, R. I., “An Experimental Investigation of Interaction of Sprays With Acoustic Fields," Experiments in Fluids, Vol. 38, No. 5, 2005, pp. 576-587, doi: $10.1007 / \mathrm{s} 00348-004-0912-1$

[39] Bind, V. K., Roy, S., and Rajagopal, C., "A Reaction Engineering Approach to Modeling Dust Explosions," Chemical Engineering Journal, Vol. 207, 2012, pp. 625-634, doi: 10.1016/j.cej.2012.07.026

[40] Chiu, H. H. and Liu, T. M., "Group Combustion of Liquid Droplets,” Combustion Science and Technology, Vol. 17, No. 3-4, 1977, pp. 127-142, doi: $10.1080 / 00102207708946823$

[41] Chiu, H. H., Kim, H. Y., and Croke, E. J., "Internal Group Combustion of Liquid Droplets," Symposium (international) on combustion, Vol. 19, No. 1, 1982, pp. 971-980, doi: 10.1016/S0082-0784(82)80273-7

[42] Nakamura, M., Akamatsu, F., Kurose, R., and Katsuki, M., "Combustion Mechanism of Liquid Fuel Spray in a Gaseous Flame," Physics of Fluids, Vol. 17, No. 12, 2005, pp. 123301, doi: $10.1063 / 1.2140294$

[43] Kitano, T., Nishio, J., Kurose, R., and Komori, S., "Effects of Ambient Pressure, Gas Temperature and Combustion Reaction on Droplet Evaporation," Combustion and Flame, Vol. 161, No. 2, 2014, pp. 551-564, doi: $10.1016 /$ j.combustflame.2013.09.009

[44] Lengellé, G., Duterque, J., and Trubert, J., “Combustion of Solid Propellants,” Tech. rep., DTIC Document, 2002.

[45] Borghi, R. and Destriau, M., Combustion and Flame: Chemical and Physical Principles, Editions Technip, 1998.

[46] Annamalai, K., Ryan, W., and Dhanapalan, S., "Interactive Processes in Gasification and Combustion-Part III: Coal/Char Particle Arrays, Streams and Clouds," Progress in Energy and Combustion Science, Vol. 20, No. 6, 1994, pp. 487-618, doi: $10.1016 / 0360-1285(94) 90002-7$

[47] Kerstein, A. R. and Law, C. K., "Percolation in Combusting Sprays I: Transition from Cluster Combustion to Percolate Combustion in Non-Premixed Sprays," Symposium (International) on Combustion, Vol. 19, No. 1, 1982, pp. 961-969, doi: 10.1016/S0082-0784(82)80272-5

[48] Schwarzkopf, J. D., Sommerfeld, M., Crowe, C. T., and Tsuji, Y., Multiphase Flows with Droplets and Particles, CRC press, 2011.

[49] Bucher, P., Yetter, R. A., Dryer, F. L., Parr, T. P., and Hanson-Parr, D., "PLIF Species and Ratiometric Temperature Measurements of Aluminum Particle Combustion in O2, CO2 and N2O Oxidizers, and Comparison with Model Calculations," Symposium (International) on Combustion, Vol. 27, No. 2, 1998, pp. 2421-2429, doi: 10.1016/S0082-0784(98)80094-5 
[50] Bucher, P., Yetter, R. A., Dryer, F. L., Parr, T. P., Hanson-Parr, D. M., and Viceni, E. P., "Flames Structure Measurement of Single, Isolated Aluminum Particles Burning in Air," Symposium (International) on Combustion, Vol. 26, No. 2, 1996, pp. 1899-1908, doi: $10.1016 / \mathrm{S} 0082-0784(96) 80012-9$

[51] Duterque, J., "Experimental Studies of Aluminum Agglomeration in Solid Rocket Motors," International Journal of Energetic Materials and Chemical Propulsion, Vol. 4, No. 1-6, 1997, doi: $10.1615 /$ IntJEnergeticMaterialsChemProp.v4.i1-6.650

[52] Marble, F. E., "Dynamics of a Gas Containing Small Solid Particles," Proceedings of the 5th AGARD Combustion and Propulsion Symposium, Pergamon Press, New York, 1963.

[53] Spalding, D. B., “Combustion of Fuel Particles,” Fuel, Vol. 30, No. 1, 1951, pp. 121-130.

[54] Godsave, G. A. E., "Studies of the Combustion of Drops in a Fuel Spray-The Burning of Single Drops of Fuel," Symposium (International) on Combustion, Vol. 4, No. 1, 1953, pp. 818-830, doi: 10.1016/S0082-0784(53)80107-4

[55] Zarko, V. E. and Glotov, O. G., "Formation of Al Oxide Particles in Combustion of Aluminized Condensed Systems," Science and Technology of Energetic Materials, Vol. 74, No. 6, 2013, pp. 139-143.

[56] Ranz, W. E. and Marshall, W. R., "Evaporation from Drops," Chemical Engineering Progress, Vol. 48, No. 3, 1952 , pp. $141-146$.

[57] Grace, J. R., Clift, R., and Weber, M. E., Bubbles, Drops and Particles, Academic Press, New York, 1978.

[58] Durand, P., Vieille, B., Lambare, H., Vuillermoz, P., Boure, G., Steinfeld, P., Godfroy, F., and Guery, J., "CPS-A Three Dimensional CFD Code Devoted to Space Propulsive Flows," AIAA paper 2000-3864, June 2000.

[59] Apte, S. and Yang, V., "Unsteady flow evolution in porous chamber with surface mass injection, part 1: Free oscillation," AIAA journal, Vol. 39, No. 8, 2001, pp. 1577-1586, doi: $10.2514 / 2.1483$.

[60] Apte, S. and Yang, V., "A large-eddy simulation study of transition and flow instability in a porous-walled chamber with mass injection," Journal of Fluid Mechanics, Vol. 477, 2003, pp. 215-225, doi: $10.1017 /$ S0022112002002987

[61] Salita, M., "Quench Bomb Investigation of Al2O3 Formation from Solid Rocket Propellants (Part II): Analysis of Data," 25th JANNAF Combustion Meeting, 1988, pp. 185-197.

[62] Durox, D., Schuller, T., Noiray, N., Birbaud, A.-L., and Candel, S., "Rayleigh criterion and acoustic energy balance in unconfined self-sustained oscillating flames," Combustion and Flame, Vol. 156, No. 1, 2009, pp. 106-119, doi: $10.1016 /$ j.combustflame.2008.07.016

[63] Flandro, G. A., "Effects of Vorticity on Rocket Combustion Stability," Journal of Propulsion and Power, Vol. 11, No. 4, 1995, pp. 607-625, doi: $10.2514 / 3.23887$

[64] Cai, W., Yang, V., and Flandro, G. A., “Turbulent Transport in Rocket Motor Unsteady Flowfield,” Solid Propellant Chemistry, Combustion, and Motor Interior Ballistics, Vol. 185, 2000, pp. 837-858, doi: $10.2514 / 5.9781600866562 .0837 .0858$

[65] Majdalani, J. and Van Moorhem, W., "Multiple-scales solution to the acoustic boundary layer in solid rocket motors," Journal of Propulsion and Power, Vol. 13, No. 2, 1997, pp. 186-193, doi: $10.2514 / 2.5168$.

[66] Zhu, M., Dowling, A., and Bray, K., "Self-Excited Oscillations in Combustors with Spray Atomizers," Journal of Engineering for Gas Turbines and Power, Vol. 123, No. 4, 2001, pp. 779-786, doi: $10.1115 / 1.1376717$ 